Article

\title{
Assessing Biodiversity in Boreal Forests with UAV-Based Photogrammetric Point Clouds and Hyperspectral Imaging
}

\author{
Ninni Saarinen ${ }^{1, *(\mathbb{D})}$, Mikko Vastaranta ${ }^{1,2}(\mathbb{D})$, Roope Näsi ${ }^{3}{ }^{(\mathbb{D})}$, Tomi Rosnell ${ }^{3}$, Teemu Hakala ${ }^{3}$, \\ Eija Honkavaara ${ }^{3}$ (D), Michael A. Wulder ${ }^{4}$, Ville Luoma ${ }^{1}$, Antonio M. G. Tommaselli ${ }^{5}$ (D), \\ Nilton N. Imai ${ }^{5}$ (i), Eduardo A. W. Ribeiro ${ }^{6}{ }^{\circledR}$, , Raul B. Guimarães ${ }^{5}$, Markus Holopainen ${ }^{1}$ \\ and Juha Hyyppä ${ }^{3}$ \\ 1 Department of Forest Sciences, University of Helsinki, P.O. Box 27, 00014 Helsinki, Finland; \\ mikko.vastaranta@uef.fi (M.V.); ville.luoma@helsinki.fi (V.L.); markus.holopainen@helsinki.fi (M.H.) \\ 2 School of Forest Sciences, University of Eastern Finland, P.O. Box-111, 80101 Joensuu, Finland \\ 3 Department of Remote Sensing and Photogrammetry, Finnish Geospatial Research Institute, \\ National Land Survey, Geodeetinrinne 2, 02431 Masala, Finland; roope.nasi@nls.fi (R.N.); \\ tomi.rosnell@nls.fi (T.R.); teemu.hakala@nls.fi (T.H.); eija.honkavaara@nls.fi (E.H.); juha.hyyppa@nls.fi (J.H.) \\ 4 Canadian Forest Service (Pacific Forestry Centre), Natural Resources Canada, 506 West Burnside Road, \\ Victoria, BC V8Z 1M5, Canada; mike.wulder@canada.ca \\ 5 Department of Cartography, São Paulo State University, Roberto Simonsen 305, 19060-900 Presidente \\ Prudente, Brazil; tomaseli@fct.unesp.br (A.M.G.T.), nnimai@fct.unesp.br (N.N.I.); raul@fct.unesp.br (R.B.G.) \\ 6 Catarinense Federal Institute, Rodovia Duque de Caxias, km 6, s/n, 89240-000 São Francisco do Sul, Brazil; \\ eduwerneck@gmail.com \\ * Correspondence: ninni.saarinen@helsinki.fi; Tel.: +358-40-516-8461
}

Received: 8 January 2018; Accepted: 20 February 2018; Published: 23 February 2018

\begin{abstract}
Forests are the most diverse terrestrial ecosystems and their biological diversity includes trees, but also other plants, animals, and micro-organisms. One-third of the forested land is in boreal zone; therefore, changes in biological diversity in boreal forests can shape biodiversity, even at global scale. Several forest attributes, including size variability, amount of dead wood, and tree species richness, can be applied in assessing biodiversity of a forest ecosystem. Remote sensing offers complimentary tool for traditional field measurements in mapping and monitoring forest biodiversity. Recent development of small unmanned aerial vehicles (UAVs) enable the detailed characterization of forest ecosystems through providing data with high spatial but also temporal resolution at reasonable costs. The objective here is to deepen the knowledge about assessment of plot-level biodiversity indicators in boreal forests with hyperspectral imagery and photogrammetric point clouds from a UAV. We applied individual tree crown approach (ITC) and semi-individual tree crown approach (semi-ITC) in estimating plot-level biodiversity indicators. Structural metrics from the photogrammetric point clouds were used together with either spectral features or vegetation indices derived from hyperspectral imagery. Biodiversity indicators like the amount of dead wood and species richness were mainly underestimated with UAV-based hyperspectral imagery and photogrammetric point clouds. Indicators of structural variability (i.e., standard deviation in diameter-at-breast height and tree height) were the most accurately estimated biodiversity indicators with relative RMSE between $24.4 \%$ and $29.3 \%$ with semi-ITC. The largest relative errors occurred for predicting deciduous trees (especially aspen and alder), partly due to their small amount within the study area. Thus, especially the structural diversity was reliably predicted by integrating the three-dimensional and spectral datasets of UAV-based point clouds and hyperspectral imaging, and can therefore be further utilized in ecological studies, such as biodiversity monitoring.
\end{abstract}


Keywords: UAS; photogrammetry; remote sensing; structural diversity; size variability; dead wood; old growth; tree species; 3D; spectral

\section{Introduction}

Biological diversity (i.e., biodiversity) can be defined in numerous ways, from the genetic diversity of a local population to variety of species in a given area and related variability of these characteristics across a landscape. Perhaps the most common approach to relate biodiversity is via relating species diversity (e.g., [1-3]), which is usually measured as number of species, in other words, species richness [4]. In addition to species diversity, structural and functional variety of a forest ecosystem can be used as measures of biodiversity. Structural variety describes variation in number of tree canopy layers, but also, the existence or absence of herbs and shrubs. Functional diversity includes particular growth strategies or environmental conditions favored by given species, for example, shade tolerant vs. light demanding and deep-rooted vs. shallow rooted [4]. Changes in forested area, forest biomass, habitat fragmentation, as well as biodiversity monitoring are increasingly important related to sustainable use of forest resources, but also maintaining the natural environments. Biodiversity is decreasing due to land-use changes, climate change, and fragmentation of habitats because of infrastructure development [5-9]. In boreal forests in Nordic countries, forestry is changing structure of the forests in addition to a small constant annual change in land-use when forests are changed for other land uses classes mainly due to urbanization. Although boreal forests are not as rich in species when compared to tropical forests, they contribute to global biodiversity by approximately one-third of the world's forested land [10]. Small changes over a large area and over time add up to have aggregate effects beyond the singular localized events. Thus, changes in boreal forests can affect both local and global biodiversity.

However, to acquire frequent and spatially extensive and detailed information on species diversity (i.e., number and distribution) is prohibitively expensive. Thus, estimating biodiversity is often based on measuring other environmental factors possible to be linked with species diversity, and therefore biodiversity. In forest ecosystems, trees are the primary producers and have a prevailing impact on forest ecosystem characteristics. Understanding relations between trees and other organisms in a forest ecosystem is required to apprehend but also identify biodiversity of the ecosystem [11]. Therefore, biodiversity can be assessed with several forest structural attributes, such as size variability, canopy cover, amount of dead wood, as well as number of tree species [11-16]. According to [17], wide variability in tree size, age, and genotype represent a diverse stand, as well as species richness. In [18], diameter-at-breast height ( $\mathrm{dbh}$ ) and height were used to describe variability in tree size, thus stand structural diversity. Indicators of biodiversity of boreal forests include amount of old growth [12,19] and deciduous [13,14] trees, as well as dead trees and decaying wood [15]. After assessing biodiversity indicators, indices describing biodiversity can be calculated and then values of these indices can be used in monitoring biodiversity in the area of interest (e.g., [20,21]).

To complement field assessments of biodiversity, remote sensing is nowadays commonly used for mapping and monitoring biodiversity indicators over large areas that may have limited accessibility [20]. Remote sensing has made it possible to reduce the amount of expensive and laborious field assessments besides improving the spatial resolution and repeatability of the biodiversity assessments. However, the extent of the area of interest as well as the definition of biodiversity to be assessed (i.e., from individual tree species to variability of biotic communities across a landscape) set requirements for remote sensing methods [22]. Remote sensing can be used for measuring various environmental parameters, such as reflectance properties and three-dimensional (3D) structure of vegetation related to biodiversity (e.g., $[23,24])$. Reflectance properties capture variation between some of the tree species $[25,26]$ as well as tree vigor $[27,28]$. Various remote sensing data sets (e.g., point clouds derived from airborne laser scanning (ALS) or optical imagery) enable characterizing forest 
structure through height, height variation, and density of the vegetation. ALS data have been used to map and monitor old deciduous trees within stands [26], stands with mixed species and multiple canopy layers [29-32], site type [33], as well as amount of dead wood [34], and canopy gaps [35], all being related to diversity of forest ecosystem. In addition, sparse ALS data was used by [36] to locate potential wildlife habitats, but concluded that information on shrub and herb layers, important habitat characteristics for game birds studied, was challenging.

During recent years, the use of unmanned aerial vehicles (UAVs) in support of forest science has increased rapidly [37-39]. The use of UAVs has enabled the on-demand collection of high spatial resolution imagery, serving to improve the resolution of photogrammetric point clouds, and therefore offer improved characterization of forest structure [40,41]. Furthermore, aerial imagery with small UAVs has been used in depicting forest characteristics that are related to biodiversity. For instance, in [42], UAV-based aerial photographs were utilized in detecting fallen trees on the ground, whereas canopy gaps were delineated from high resolution RGB images acquired with a UAV in [43]. Point clouds were generated from RGB imagery to characterize forest canopy structure in $[44,45]$. In addition, UAV-based hyperspectral imagery has been utilized in identifying individual tree species [25], as well as damaged and dead trees [46]. However, these studies have not included more than one forest attributes considered important for biodiversity. In addition, in the above-mentioned studies the attributes of interest were assessed at individual tree-level. Biodiversity assessments beyond single or few stands would require at least plot-level attributes.

Although remote sensing has improved quality of the biodiversity assessments for large areas, quality of an assessment is still heavily dependent on the availability and quality of field data. The data collected from a limited number of field plots is used for linking remote sensing measurements to the attributes of interests. For example, forest structure measured with laser scanning describes height and density of vegetation [47], but does not necessarily directly provide the same attributes that are important for biodiversity assessments, such as variation in tree size and species, or the amount of dead wood. Thus, prediction models are usually developed for each mapping and monitoring campaign used for biodiversity assessments. However, some of the important biodiversity indicators that are required for building prediction models could be measured detailed enough by using high resolution remote sensing data collected with UAVs. This information could serve supplement or replace part of the currently required field work to support biodiversity assessments [48]. It should be pointed out that at least so far, UAVs are not capable for large area mapping and thus remote sensing data collected using airborne and satellite sensors is required for that purpose. Nevertheless, UAVs have shown potential in offering scale-appropriate information for biodiversity assessment in temperate forest through canopy gaps, for example [49].

With high spatial and temporal resolution at reasonable costs [50], the potential of UAVs can be expanded to enhancing sampling for large area inventories. In [37], it was suggested that UAVs could be used in identifying forest areas in need for management, such as thinning or fertilizer to concentrate activities for those and increase efficiency that way. Similarly in assessing biodiversity, UAVs can be seen as support tool when planning field campaigns. For example, in multi-phase sampling where airborne or satellite data are usually used for stratifying the first phase of sampling for biodiversity mapping, UAVs could be used in second phase before determining the final field plots. In other words, data from a UAV would be complementary for part of the traditional field measurements that can be accurately derived from UAV data (e.g., vegetation height, canopy gaps) [37,43,51].

The aim of this study is to increase the understanding and capacity for how important biodiversity indicators can be mapped using spectral and 3D features based on hyperspectral imagery and photogrammetric point clouds acquired with a UAV in southern boreal forest conditions at plot level. In our study, the investigated biodiversity indicators included stand successional stage (maturity), amount of old deciduous trees, structural diversity, and the amount of dead wood. We concentrated on how accurately we can derive these biodiversity indicators that can in turn be further used to support biodiversity assessments for large areas based on remote sensing. 


\section{Materials and Methods}

\subsection{Field Reference}

The study was carried out in southern Finland $\left(61.19^{\circ} \mathrm{N}, 25.11^{\circ} \mathrm{E}\right)$ over an approximately 2000 ha area, including both managed and natural southern boreal forests. Stands are characterized as mainly even aged and single layered with an average size slightly less than 1 ha. The main tree species are Scots pine (Pinus sylvestris L.), Norway spruce (Picea abies (L.) Karst), and silver and downy birches (Betula pendula and pubescens L.). The study includes 28 rectangular sample plots size of $32 \mathrm{~m} \times 32 \mathrm{~m}$ in varying forest condition (Table 1), and in addition to the main tree species, other deciduous tree species, such as aspen (Populus tremula L.), as well as Grey and Common alder (Alnus incana (L.) Moench, and glutinosa (L.) Gaertn.) occurred.

Table 1. Statistics describing forest inventory attributes of the sample plots. Dg = basal-area weighted mean diameter-at-breast height, $\mathrm{Hg}=$ basal-area weighted mean height, $\mathrm{G}=$ basal area, $\mathrm{V}=$ stem volume, $\mathrm{AGB}=$ total aboveground biomass, and $\mathrm{H}_{\mathrm{st.dev}}=$ standard deviation of field measured tree heights at plot level.

\begin{tabular}{ccccc}
\hline Attribute & Minimum & Maximum & Mean & Standard Deviation \\
\hline $\mathrm{Dg}(\mathrm{cm})$ & 14.03 & 35.08 & 23.69 & 5.60 \\
$\mathrm{Hg}(\mathrm{m})$ & 10.48 & 26.63 & 20.20 & 3.90 \\
$\mathrm{G}\left(\mathrm{m}^{2} / \mathrm{ha}\right)$ & 5.80 & 41.69 & 25.46 & 7.28 \\
$\mathrm{~V}_{\text {live }}\left(\mathrm{m}^{3} / \mathrm{ha}\right)$ & 31.36 & 417.14 & 249.11 & 92.10 \\
$\mathrm{~V}_{\text {Scots pine }}\left(\mathrm{m}^{3} / \mathrm{ha}\right)$ & 0.00 & 280.41 & 75.78 & 93.56 \\
$\mathrm{~V}_{\text {Norway spruce }}\left(\mathrm{m}^{3} / \mathrm{ha}\right)$ & 0.00 & 337.89 & 115.36 & 113.21 \\
$\mathrm{~V}_{\text {Birch }}\left(\mathrm{m}^{3} / \mathrm{ha}\right)$ & 0.08 & 171.07 & 45.53 & 47.71 \\
$\mathrm{~V}_{\text {Aspen }}\left(\mathrm{m}^{3} / \mathrm{ha}\right)$ & 0.00 & 204.09 & 11.02 & 38.13 \\
$\mathrm{~V}_{\text {Alder }}\left(\mathrm{m}^{3} / \mathrm{ha}\right)$ & 0.00 & 8.19 & 0.79 & 1.71 \\
$\mathrm{~V}_{\text {Dead }}\left(\mathrm{m}^{3} / \mathrm{ha}\right)$ & 0.00 & 17.21 & 3.08 & 4.02 \\
$\mathrm{AGB}_{\text {live }}($ tons $/$ ha $)$ & 17.27 & 225.87 & 128.80 & 45.13 \\
Number of trees $(/$ ha $)$ & 342 & 3008 & 1063 & 557 \\
Number of dead trees $(/$ ha $)$ & 0 & 137 & 38 & 43 \\
$\mathrm{H}_{\text {st.dev }}(\mathrm{m})$ & 2.16 & 11.00 & 5.46 & 2.14 \\
\hline
\end{tabular}

Field measurements were carried out during the summer of 2014. Every tree with dbh larger than $5 \mathrm{~cm}$ was identified and tree species, health status (i.e., live, dead, snag), dbh, and height were determined for these trees. Existing allometric models [52-54] were used to calculate stem volume and biomass for each tree. This information was used to aggregate species-specific forest inventory attributes, such as, basal-area weighted mean dbh, basal-area weighted mean height, basal area, volume, and total aboveground biomass, for plot level. In addition to these traditional attributes, standard deviation of tree heights as well as number and volume of dead trees were calculated. If a tree was classified as a snag, it was included in the analysis, as it was assumed that the cut part also was within the plot and should be considered in the amount of dead wood. Descriptive statistics depicting individual trees are presented in Table 2.

Table 2. Statistics describing individual trees within the sample plots. dbh = diameter-at-breast height, $\mathrm{h}=$ height, $\mathrm{v}=$ stem volume, and AGB = total aboveground biomass.

\begin{tabular}{cccccc}
\hline & Attribute & Minimum & Maximum & Mean & Standard Deviation \\
\hline \multirow{5}{*}{ Live trees } & $\mathrm{dbh}(\mathrm{cm})$ & 4.8 & 47.9 & 15.9 & 8.1 \\
& $\mathrm{~h}(\mathrm{~m})$ & 2.0 & 31.9 & 15.7 & 6.4 \\
& $\mathrm{v}\left(\mathrm{dm}^{3}\right)$ & 4.7 & 2258.9 & 243.5 & 295.4 \\
& $\mathrm{AGB}(\mathrm{kg})$ & 3.7 & 1084.5 & 125.9 & 146.3 \\
\hline \multirow{5}{*}{ Dead trees } & $\mathrm{dbh}(\mathrm{cm})$ & 5.0 & 32.5 & 10.9 & 6.3 \\
& $\mathrm{~h}(\mathrm{~m})$ & 1.4 & 25.1 & 8.4 & 5.0 \\
& $\mathrm{v}\left(\mathrm{m}^{3}\right)$ & 5.1 & 861.3 & 82.6 & 150.8 \\
& $\mathrm{AGB}(\mathrm{kg})$ & 3.2 & 431.9 & 45.3 & 83.3 \\
\hline
\end{tabular}




\subsection{Biodiversity Indicators}

Biodiversity indicators that are used in this study include variability in both species and structural attributes. Species richness was defined as the amount of different tree species, i.e., stem number and volume per hectare was determined for each tree species that were defined during field measurements (Table 3). In addition, stem number and volume per ha of dead trees were determined based on the field measurements for each sample plot, as dead wood is one of the factors biodiversity can be assessed with. Structural heterogeneity is also seen as contributing in biodiversity, thus, variation in $\mathrm{dbh}$ and tree height were used as indicators for size variability. Basal-area-weighted mean diameter was used as an indicator for successional stage as that is the attributed used for determining developmental class, in other words, maturity, in Finland. As large deciduous trees are considered important indicators for biodiversity the volume and number of deciduous trees with $\mathrm{dbh}>25 \mathrm{~cm}$ were calculated per each tree species identified from the sample plots.

Table 3. Indicators used to assess for biodiversity.

\begin{tabular}{lll}
\hline \multicolumn{1}{c}{ Biodiversity Indicator } & \multicolumn{1}{c}{ Attribute (Unit) } & \multicolumn{1}{c}{ Definition for the Attribute } \\
\hline Species richness & $\begin{array}{l}\text { Volume }\left(\mathrm{m}^{3} / \mathrm{ha}\right) \text { and number of } \\
\text { trees }(\mathrm{N} / \mathrm{ha}) \text { of each tree species }\end{array}$ & \\
\hline Amount of dead wood & $\begin{array}{l}\text { Volume }\left(\mathrm{m}^{3} / \mathrm{ha}\right) \text { and number } \\
(\mathrm{N} / \mathrm{ha}) \text { of dead trees }\end{array}$ & Include both horizontal and vertical variation \\
\hline Structural heterogeneity & $\begin{array}{l}\text { Standard deviation in dbh }(\mathrm{cm}) \\
\text { and tree height }(\mathrm{m})\end{array}$ & $\begin{array}{l}\text { Used in Finnish forest management planning } \\
\text { for determining developmental class, i.e., } \\
\text { maturity or successional stage }\end{array}$ \\
\hline Successional stage & $\begin{array}{l}\text { Basal-area-weighted mean } \\
\text { diameter }(\mathrm{cm})\end{array}$ & $\begin{array}{l}\text { Large trees were defined as dbh }>25 \mathrm{~cm}, \\
\text { because it is the minimum dbh limit for } \\
\text { regeneration according to Good forest } \\
\text { management practices in Finland }\end{array}$ \\
\hline Amount of large deciduous trees & $\begin{array}{l}\text { Volume }\left(\mathrm{m}^{3} / \mathrm{ha}\right) \text { and number } \\
(\mathrm{N} / \mathrm{ha}) \text { of deciduous trees with } \\
\text { dbh }>25 \mathrm{~cm}\end{array}$ & \\
\hline
\end{tabular}

\subsection{The Remote Sensing Data Captured by a UAV}

The remote sensing datasets were captured using a hyperspectral two-dimensional (2D)-format frame camera and an RGB camera. The hyperspectral camera was based on a tuneable Fabry-Pérot interferometer (FPI) and manufactured by Senop Ltd. (Oulu, Finland). The FPI camera provided hyperspectral images with 22 spectral bands in the spectral range from visible to near-infrared (NIR) (between $500 \mathrm{~nm}$ and $900 \mathrm{~nm}$ ) and with the full width at half maximum (FWHM) of typically less than $13 \mathrm{~nm}$ (Table 4). Separation between adjacent bands varied from $7.4 \mathrm{~nm}$ to $52.1 \mathrm{~nm}$, and was $18.6 \mathrm{~nm}$ on average, thus the spectral data were not exactly contiguous over the full spectra. However, we considered the data hyperspectral because it was possible to select the bands that represented well the spectral characteristics of the objects of interest. The FPI camera captured 2D-format hypercubes with $600 \times 1010$ pixels, but due to the tuneable filter technology the spectral bands were collected sequentially causing spatial misalignment of the bands [40,55]. The RGB camera was a low-cost consumer mirrorless Samsung NX300 camera used for obtaining imagery with high spatial resolution for generating 3D point clouds. The camera was equipped with a $16-\mathrm{mm}$ fixed lens and a CMOS APS-C size sensor with an image size of $5472 \times 3648$ pixels. 
Table 4. Spectral settings of the spectral camera. L0: central wavelength, FWHM: full width at half maximum.

\begin{tabular}{cl}
\hline \multirow{2}{*}{ L0 (nm) } & $504.02,528.91,554.20,579.10,603.92,629.03,681.14,688.68,696.15,704.25,711.68$, \\
& $719.29,726.68,734.31,742.38,750.20,775.26,800.16,824.89,850.24,874.71,900.05$ \\
\hline \multirow{2}{*}{ FWHM (nm) } & $12.61,14.10,12.85,12.91,12.60,12.22,11.88,12.59,11.78,11.54,11.44,11.72,12.04,11.71$, \\
& $11.30,11.04,11.92,10.97,10.95,10.97,12.92,17.82$ \\
\hline
\end{tabular}

The UAV imagery was acquired during two days in early July in 2014 with weather conditions varying from sunny to cloudy (Table 5). A single-rotor UAV helicopter based on Mikado Logo 600 mechanics with a 5-kg payload capacity was used for capturing the remote sensing datasets. The two cameras were fixed to the landing gears of the UAV and operated simultaneously. A preprogrammed flight path was flown autonomously using autopilot DJI ACE Waypoint. The altitude was $400 \mathrm{~m}$ resulting in a ground sampling distance (GSD) of $0.25 \mathrm{~m}$ for the hyperspectral and $0.10 \mathrm{~m}$ for the RGB imagery. The flying speed was $10 \mathrm{~m} / \mathrm{s}$ and the distance between flight lines was $110 \mathrm{~m}$ providing $95 \%$ forward and $80 \%$ side overlap for the RGB imagery, and $87 \%$ and $55 \%$ for the FPI imagery, respectively. The footprints of the FPI images were $163 \mathrm{~m}$ by $249 \mathrm{~m}$, and of the RGB images $392 \mathrm{~m}$ by $588 \mathrm{~m}$. We collected a total of 11 datasets in separate flights, but rejected four FPI-datasets due to technical problems or inadequate data quality. Datasets from three flights were rejected because there appeared a light leak in the images due to missing cover during the flights. In addition, one flight was rejected because of unsatisfactory data quality caused by highly varying cloud cover resulting in too serious illumination variations (beyond what could be corrected by post-processing). Finally, seven datasets were included in this study with both the FPI and RGB images from the 28 sample pots.

Table 5. Details of the UAV data capture: date, time, weather, altitude, flight speed, exposure time of the spectral camera, and information about radiometric model used for spectral images (rel = relative image-wise corrections; BRDF = bidirectional reflectance distribution function correction).

\begin{tabular}{|c|c|c|c|c|c|c|c|}
\hline Dataset & Date & $\begin{array}{l}\text { Local Time } \\
(\mathrm{UTC}+3)\end{array}$ & $\begin{array}{l}\text { Weather } \\
\text { Conditions }\end{array}$ & Altitude (m) & Flight Speed (m/s) & $\begin{array}{c}\text { Exposure } \\
\text { Time (ms) }\end{array}$ & $\begin{array}{c}\text { Radiometric } \\
\text { Model }\end{array}$ \\
\hline F2 & 5 July 2014 & 11:31-11:49 & Sunny & 400 & 10 & 25 & rel, BRDF \\
\hline F3 & 5 July 2014 & $13: 20-13: 45$ & Varying & 400 & 10 & 25 & rel, BRDF \\
\hline $\mathrm{F} 4$ & 5 July 2014 & $14: 31-15: 55$ & Cloudy & 400 & 10 & 30 & rel \\
\hline F5 & 6 July 2014 & 8:09-8:37 & Sunny & 400 & 10 & 20 & rel, BRDF \\
\hline F7 & 6 July 2014 & 11:43-12:08 & Varying & 400 & 10 & 25 & rel, BRDF \\
\hline F9 & 6 July 2014 & $13: 57-14: 23$ & Varying & 400 & 10 & 25 & rel, BRDF \\
\hline F10 & 6 July 2014 & $15: 57-16: 23$ & Sunny & 400 & 10 & 25 & rel, BRDF \\
\hline
\end{tabular}

We deployed 15 signaled ground control points (GCPs) in the study area for georeferencing purposes. Their coordinates were measured using the virtual reference station real-time kinematic GPS (VRS-GPS) with an accuracy of $0.03 \mathrm{~m}$ in horizontal coordinates and $0.04 \mathrm{~m}$ in height. Furthermore, 30 photogrammetric control points were identified from national open topographic datasets, in other words, orthophoto and a national ALS-based digital terrain model (DTM) covering the study area provided by the National Land Survey of Finland (NLS). Reflectance reference panels with the size of $1 \mathrm{~m} \times 1 \mathrm{~m}$ and nominal reflectance of $0.03,0.09$, and 0.50 were installed in ground station for determining the reflectance transformation. In addition, an irradiance spectrometer ASD FieldSpec Pro was installed on the area to monitor the illumination conditions. The seven datasets used in this study and the distribution of the GCPs and reflectance panels are shown in Figure 1. 


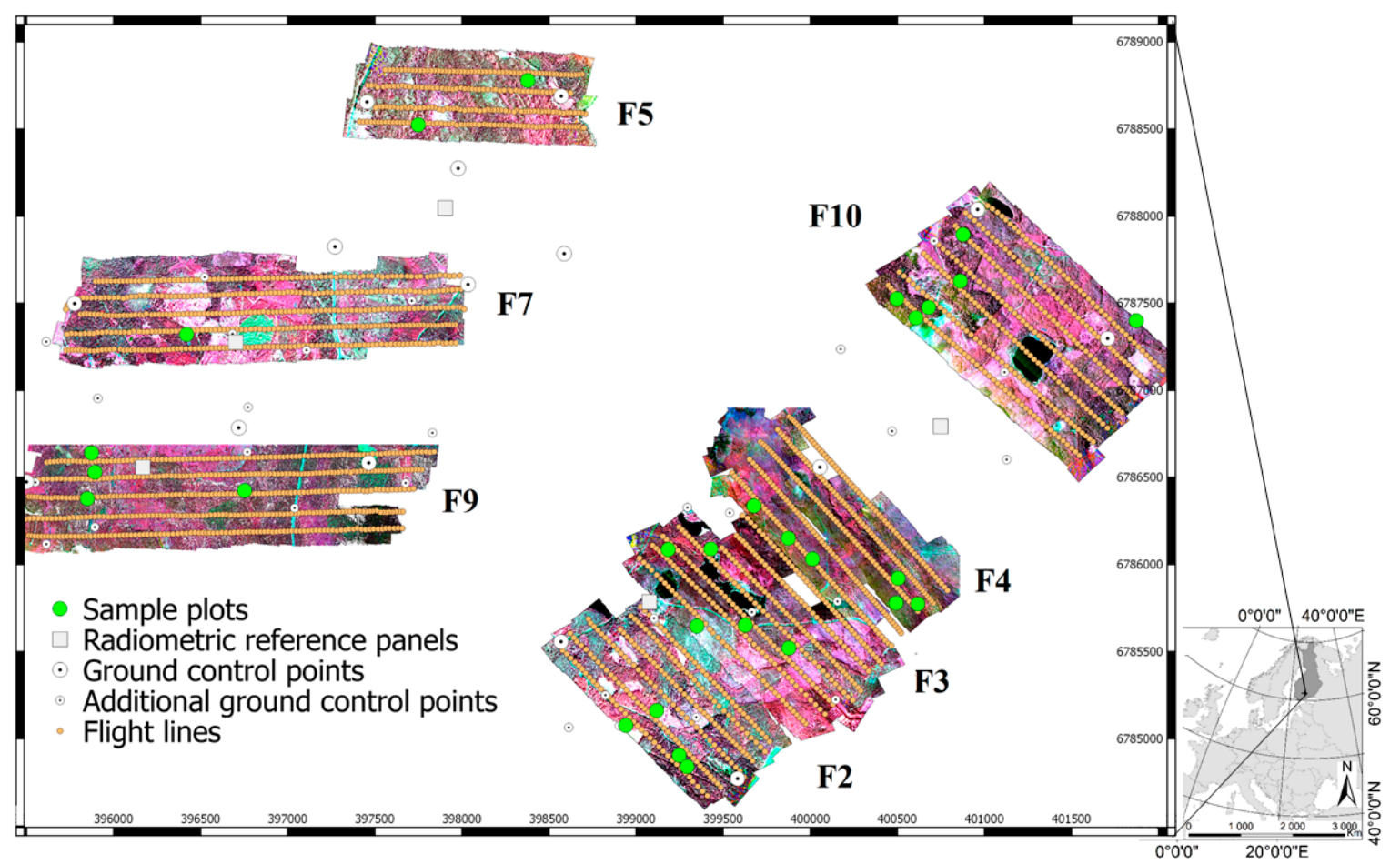

Figure 1. The reflectance orthomosaic composites of spectral bands with central wavelengths of $850 \mathrm{~nm}$, $681 \mathrm{~nm}$, and $554 \mathrm{~nm}$ of the seven remote sensing datasets used in this study. Locations of sample plots, radiometric reference panels, ground control points, and flight lines in the study area.

\subsection{Calculation of Dense Point Clouds and Image Mosaics}

The data processing included determining orientations of the both FPI and RGB images, creating dense 3D point clouds using the RGB images, the radiometric processing and mosaic calculation of the FPI images, and combining the radiometrically corrected hyperspectral datasets with the 3D point clouds.

The orientation processing of the FPI-camera images followed the processing chain developed by [55]. We chose one band (i.e., band 10: $\mathrm{L} 0=704.25 \mathrm{~nm}$ ) to determine the exterior and interior orientations of the FPI images. The self-calibrating bundle block adjustments supported with the GCPs were calculated using the Socet GXP (BAE Systems, San Diego, CA, USA) commercial software. The datasets were processed in five sub-blocks having 464-147 images and 8-15 flight lines. The adjustment results indicated geometric accuracy of approximately $1 \mathrm{~m}$. An additional band-matching process was necessary for the FPI images because of the misregistration of the individual bands due to the imaging principle of the FPI camera. All of the bands were matched to the reference band 10 using Coregisteting version 1.1 software by Senop Ltd. that is based on a feature-based matching algorithm, and a 2D transformation to map the bands to the reference band.

The geometric processing of the RGB images for generating 3D point clouds was carried out using the Smart3DCapture Expert edition Acute3D software [56]. Orientations were determined separately for seven sub-blocks with 401-709 images and 5-14 flight lines. The aim of the dense matching was to create 3D point clouds with a point interval corresponding to the GSD, thus accuracy settings of ultra-high were used. The generated photogrammetric point clouds corresponded with the national ALS data, indicating satisfactory photogrammetric processing. In addition, a digital surface model (DSM) with a GSD of $0.1 \mathrm{~m}$ was created from the generated point clouds to be used in the orthorectification of the hyperspectral data.

The objective of the radiometric processing of the FPI imagery was to provide high quality reflectance mosaics, including the 22 spectral bands. The radiometric modelling approach developed 
at the Finnish Geospatial Research Institute (FGI) included sensor corrections, atmospheric correction, correction for the illumination changes and other non-uniformities, and normalization of the anisotropy effects due to the varying illumination and viewing directions [55]. We used the empirical line method [57] to calculate the transformation from digital numbers to reflectance factors with the aid of the reflectance reference panels. Some of the datasets included partially cloudy images that were excluded from the processing. A radiometric block-adjustment method was used to determine the model-based radiometric correction to compensate for the remaining radiometric disturbances. In this investigation, the relative image-wise correction parameters were calculated for all seven datasets. Furthermore, disturbances caused by the object-reflectance anisotropy (i.e., bidirectional reflectance distribution function (BRDF)) were determined for the datasets that were collected during sunny weather (Table 5). The BRDF-correction was determined from the image data and it was based on the BRDF-model that was estimated using intensity information of radiometric tie points appearing in the overlapping images; the procedure is described in detail in $[55,58]$. Finally, the reflectance orthophoto mosaics were calculated to the nadir view geometry with a GSD of $50 \mathrm{~cm}$ using the image orientations, DSM, and the radiometric model.

In this study, dense 3D point clouds based on the RGB imagery and spectral reflectance mosaics were combined by searching reflectance values for each $3 \mathrm{D}$ point from reflectance orthophoto mosaics. Thus, the final remote sensing data included the 3D coordinates, as well as reflectance values for the 22 spectral bands.

\subsection{Segmentation of Digital Surface Model and Extration 3D Metrics from Image-Based Point Clouds}

For detecting tree crowns (i.e., segmentation), DSMs with a resolution of $0.3 \mathrm{~m}$ was created from the photogrammetric point clouds covering each sample plot. The original DSMs with GSD of $0.1 \mathrm{~m}$ were not used for the segmentation as there were gaps in them and interpolation resulted in variability in elevation values of adjacent cells and would have caused more uncertainty in the segmentation [59]. In addition, the resolution of $0.3 \mathrm{~m}$ corresponded better with the GSD of the FPI images (i.e., $0.25 \mathrm{~m}$ ). To delineate tree crowns from the DSM of each plot, we carried out watershed segmentation in ArcMap (version 10.3) and finally, the created segments were associated with the field-measured trees using their spatial information.

The photogrammetric point clouds were normalized with the national DTM based on ALS with a resolution of $2 \mathrm{~m}$, as provided by the NLS. Metrics describing height and density of each crown segment within the sample plots were generated from the normalized point clouds. The generated metrics (Table 6) included descriptive statistics, including maximum height (Hmax), mean height defined as the arithmetic mean of heights (Hmean), standard deviation of heights (Hstd), as well as the coefficient of variation of heights $(\mathrm{Hcv})$ of points. Furthermore, quantiles for every $10 \%$ representing the height of certain percentage of vegetation points (i.e., percentiles) were calculated between $10 \%$ and $90 \%\left(\mathrm{HP}_{10}-\mathrm{HP}_{90}\right)$.

Table 6. Metrics generated from the normalized image-based point clouds.

\begin{tabular}{cc}
\hline Metrics & Definition \\
\hline Hmax & Maximum of the normalized heights of all points \\
$\mathrm{H}_{\text {mean }}$ & Arithmetic mean of normalized heights of all points \\
$\mathrm{HP}_{10}-\mathrm{HP}_{90}$ & Percentiles from $10 \%$ to $90 \%$, in every $10 \%$, of normalized heights of all points \\
Hstd & Standard deviation of normalized heights of all points \\
$\mathrm{Hcv}$ & Coefficient of variation of normalized heights, calculated as Hstd $/ \mathrm{Hmean}$ \\
\hline
\end{tabular}

\subsection{Extration of Spectral Features}

The FPI imagery consisted of 22 spectral bands. The spectral features were generated for each of the spectral band separately from the reflectance values of points within a segment. The generated spectral features included arithmetic mean spectra (Smean) and median spectra (Smedian), as well 
as percentiles between $10 \%$ and $100 \%\left(\mathrm{SP}_{10}-\mathrm{SP}_{100}\right)$, characterizing the brightness of points within each segment.

In addition to spectral features, different normalized channel ratios (i.e., vegetation indices) were computed by applying Equation (1) with the reflectance of two bands.

$$
\text { Index }=\frac{\left(R_{\lambda 1}-R_{\lambda 2}\right)}{\left(R_{\lambda 1}+R_{\lambda 2}\right)}
$$

where $R$ is the reflectance value and $\lambda_{1}$ and $\lambda_{2}$ are the wavelengths of the two bands employed in the index. First, we computed a normalized difference vegetation index (NDVI), including NIR and red channels. Additionally, a green normalized difference vegetation index (GNVDI) using NIR and green spectrum instead of the red spectrum was computed. The third index was based on NIR and red edge bands that were defined here between $700 \mathrm{~nm}$ and $780 \mathrm{~nm}$ (e.g., [60]). Since there were more than one wavelength describing a band, the difference and utility of each band for differentiating tree species and health class from each other was tested generating each index with all possible combination of wavelengths.

\subsection{Predicting Biodiversity Indicators}

A non-parametric method using nearest neighbor estimation was used for predicting tree height, $\mathrm{dbh}$, and volume, as well as species and health status for each crown segment from which the biodiversity indicators were aggregated for the sample plots. In our nearest neighbor method, the statistical distance between the target and reference samples (i.e., crown segments) were calculated. A random forest classification method [61] was applied to calculate these distances that are defined as a probability of ending in the same terminal node in a classification tree generated by the random forest method. In the random forest neighbor search, a large number of predictors can be included without a risk of overfitting [62]. However, robust models were desired, thus, the number of final predictors was reduced considerably from the initial set of predictors. Random forest was employed for selecting the most important 3D metrics and spectral features as well as wavelengths utilized for calculating vegetation indices. Random forest was run 100 times to first identify the most important 3D metrics for predicting dbh and height. Then, spectral features and vegetation indices of all possible wavelength combinations were identified based on their scaled importance in 100 random forest classifications for health status (i.e., live or dead) and tree species, as well as species group (i.e., conifer and deciduous) separately. Final selection was done from those spectral features and vegetation indices that were considered the most important variable at least 10 times of the 100 random forest runs. If they were correlated $(r>0.75)$, only the most important variable was selected. First, the spectral features and vegetation indices for classifying health status were selected, then the ones for species group.

We did not want to lose the information of large trees that are considered to be more important to biodiversity than medium sized or small trees. In other words, we wanted to avoid shifting especially the extreme predictions towards the sample mean, thus, the number of neighbors was set to 1. In addition, the main interest here was not in the accuracy of estimated attributes for individual segments, but the ones at plot level. The prediction was done with the selected 3D metrics and spectral features as well as with the selected 3D metrics and vegetation indices.

The prediction was based on an assumption that each crown segment would include only one tree, in other words, using individual tree-crown approach (ITC), but also following the idea by [63] of so-called semi-individual tree-crown approach (semi-ITC) where a crown segment could include none, one, or several trees. In ITC, if there were more than one field-measured tree associated with a segment the tallest tree was selected, whereas in semi-ITC it was possible that one segment was associated with several field-measured trees (Figure 2). In ITC, the tree-level attributes, such as dbh, height, and volume, as well as species and health status (i.e., live, dead) were predicted for each crown segment, whereas in semi-ITC the prediction for each crown segment resulted in a list of the tree-level attributes (as there could be one or more trees within a crown segment). 


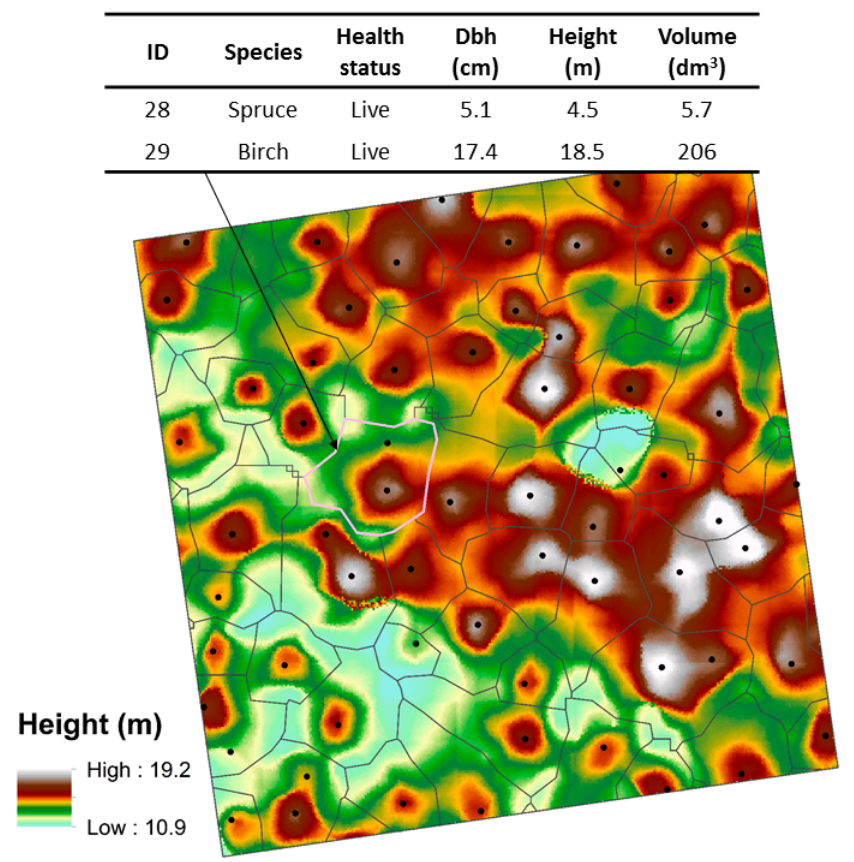

Figure 2. An example of individual tree-crown approach (ITC) and semi-individual tree-crown approach (semi-ITC). In ITC, only the birch, being the tallest tree within the segment, would be considered in the predictions whereas in semi-ITC information on both spruce and birch would be included in the predictions.

The estimates for biodiversity indicators were validated at the sample-plot level using a modified leave-one-out cross-validation method. In other words, we excluded the reference data from the $i$ th sample plot at a time and developed nearest neighbor estimation models using the crown segments and remote sensing features from the remaining sample plots. The tree-level attributes were then predicted for all the crown segments within the $i$ th sample plot that was left out from the model development. Plot-level biodiversity indicators based on either ITC or semi-ITC were then aggregated. The process was iterated for all the 28 sample plots. The accuracy assessment was carried out at plot level and both absolute and relative root-mean square error (RMSE) and bias were calculated for all biodiversity indicators. In addition, field-measured biodiversity indicator was subtracted from the predicted value (i.e., error) and its effect as a function of total volume was analyzed.

\section{Results}

\subsection{Predictor Selection}

From the 3D metrics, Hmax was the best classifier for tree height and dbh from all the 100 random forest classification runs. Thus, the Hmax was selected 3D metrics for the final predictions. Visual inspection of the mean spectra revealed that the dead trees had lower reflectance values, especially in the NIR part of the spectrum (Figure 3). Average difference between mean and median spectra between tree species was approximately 0.00 , indicating relatively uniformly distributed species-specific spectral values without any noteworthy outliers. For dead trees, on the other hand, the difference between mean and median spectra varied from 0.01 to 0.02 between the bands with wavelength from $719 \mathrm{~nm}$ to $775 \mathrm{~nm}$, corresponding on average $27.6 \%$ of the mean reflectance values. This difference is also visible in Figure 3. 

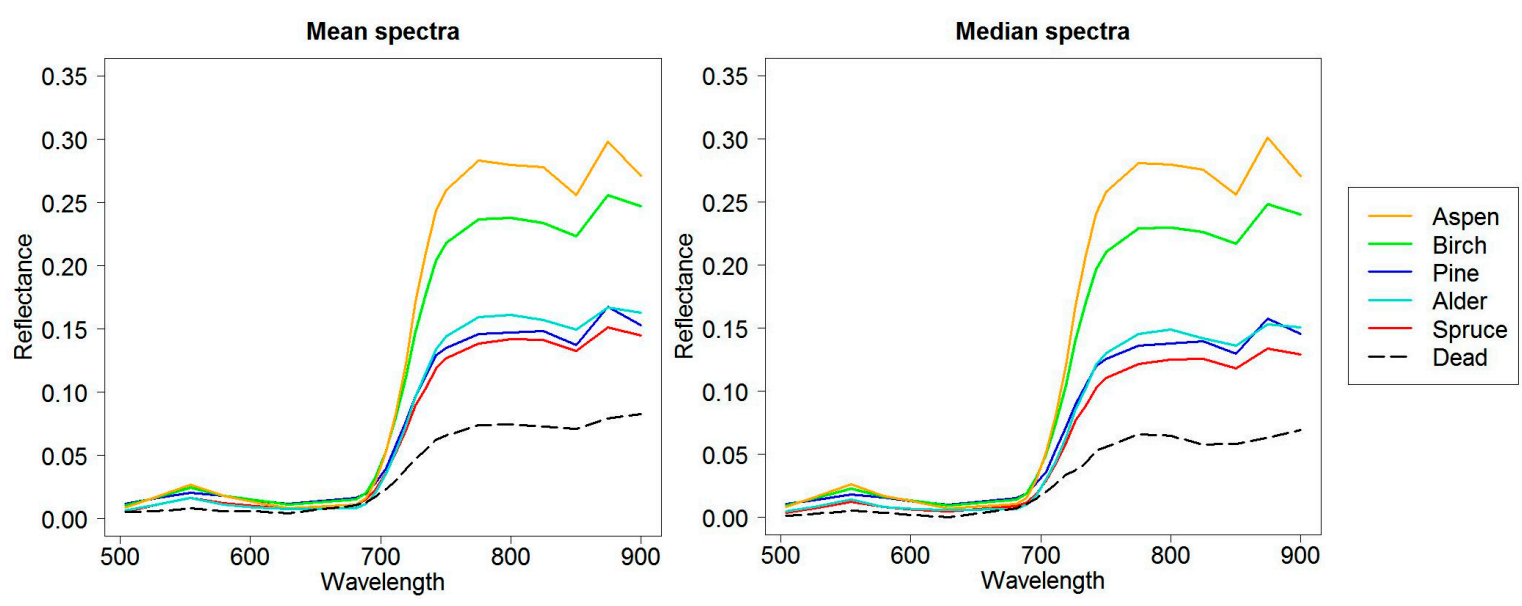

Figure 3. Mean (left) and median (right) spectra of various tree species (only live trees included) and dead trees.

Based on the 100 random forest classification runs, the most important spectral feature for health status was 3rd percentile for a red-edge band of $742 \mathrm{~nm}$, whereas for species group it was 1st percentile for a red band of $629 \mathrm{~nm}$ and for individual tree species it was 2nd percentile of green band of $504 \mathrm{~nm}$. For health status and species group there were also other spectral features that were identified as the most important attribute more than 10 times during the 100 random forest classification runs. They were, however, correlated $(r>0.75)$ with the above-mentioned features and were thus, discarded in the final selection.

When selecting vegetation indices for the predictions, there was only one vegetation index identified more than 10 times during the random forest classification runs for health status and it was an index using red-edge band of $742 \mathrm{~nm}$ and NIR band of $900 \mathrm{~nm}$. For species group and individual tree species, there were two indices, namely using two re-edge bands (i.e., $742 \mathrm{~nm}$ and $750 \mathrm{~nm}$ ) and one NIR band (i.e., $824 \mathrm{~nm}$ ), identified more than 10 times during the random forest runs for both classifications, and they were selected for final predictions.

\subsection{Accuracy of Predicted Biodiversity Inidcators}

Variation in dbh was the most accurately predicted biodiversity indicator (Figure 4 and Table 6). When spectral features were included in the predictions, together with Hmax, it was possible to capture more variability in dbh with semi-ITC as it resulted in a RMSE of $24.36 \%$ when compared to ITC resulting in a RMSE of $30.19 \%$. The relative RMSEs for dbh variability were $27.57 \%$ with semi-ITC and $32.75 \%$ with ITC when vegetation indices together with Hmax were used. Comparable relative RMSE values were obtained for height variation (with semi-ITC).

The amount of pine, spruce, and birch was predicted more accurately compared to aspen and alder that were mainly mixed with the three main tree species. The volume of large deciduous trees was overestimated with all methods similarly to volume of all deciduous trees (also when species were predicted separately) with the ITC when vegetation indices were included in the predictions (Tables 7 and 8). The smallest relative bias with ITC was obtained for volume estimate of broadleaved species with spectral features $(5.62 \%)$, whereas ITC with vegetation indices resulted in smallest bias for volume estimate for birch $(-10.71 \%)$. With semi-ITC, on the other hand, the smallest bias was obtained with spectral features for volume of alder with $(0.18 \%)$ and for standard deviation of dbh $(-0.43 \%)$, corresponding absolute bias of $-0.03 \mathrm{~cm}$. In addition, the bias for standard deviation of tree height was $1.92 \%(0.11 \mathrm{~m})$ with semi-ITC and spectral features.

There was more bias in predictions of tree species with semi-ITC as compared to ITC (Table 8). However, there was no clear trend in the plot-level error (Figure 5), an indicator that the main source of error was in classifying tree species correctly. If a prediction for tree species was not correct for a large tree, the errors of both species increased. For example, if a large birch was classified as a pine there 
was overestimate for pine and underestimate for birch. Nevertheless, underestimates in volume of dead trees increased when there were more dead trees within a plot (Figure 6), indicating that also health status (i.e., live or dead) was a major error source. Analogous tendency can be observed for biodiversity indicators representing structural heterogeneity (i.e., standard deviation in dbh and tree height) although not as strong.
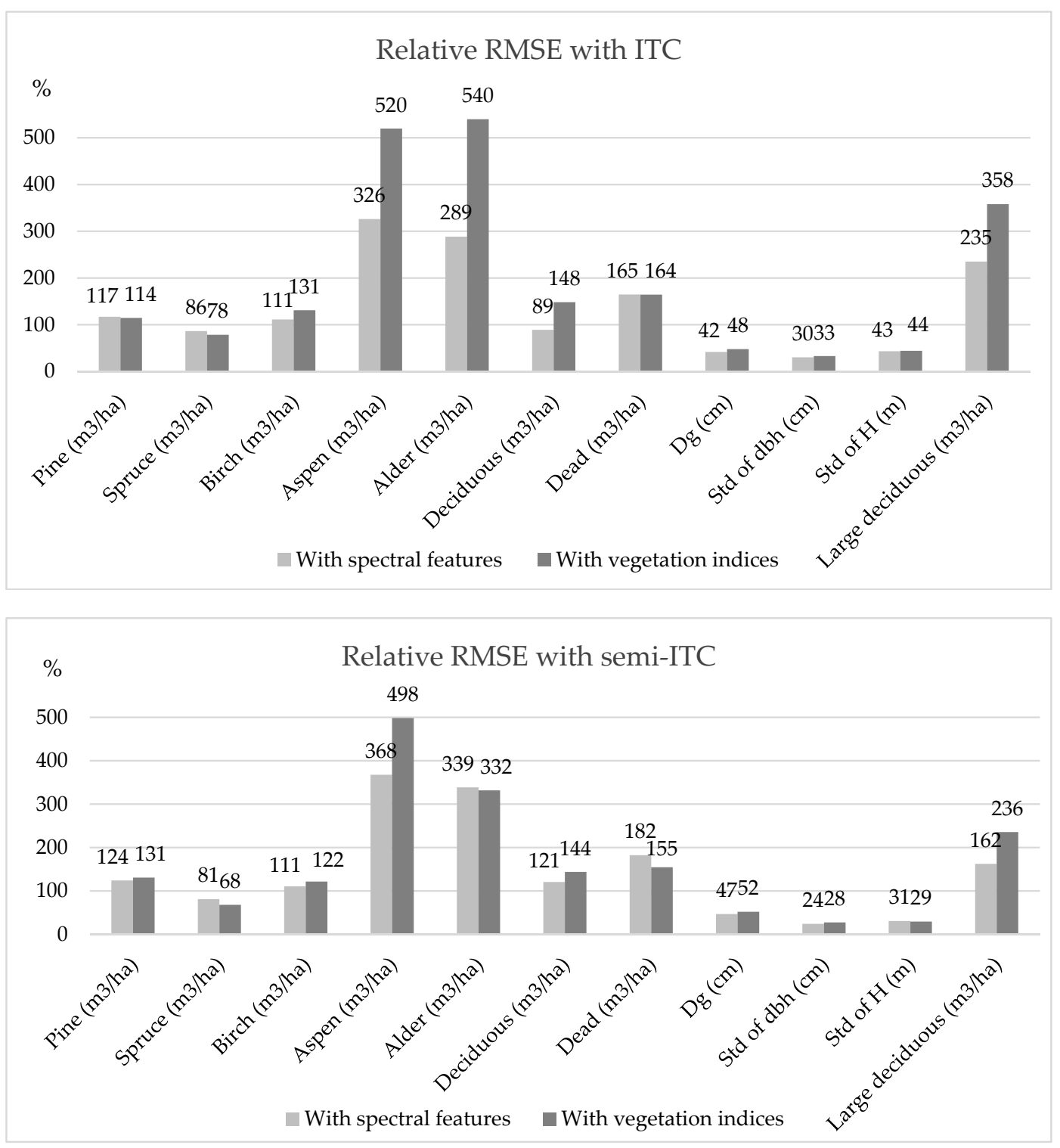

Figure 4. Accuracy of attributes characterizing biodiversity indicators estimated with individual tree crown approach (ITC) (above) and semi-individual tree crown approach (semi-ITC) (below). With both approaches biodiversity indicators were estimated using structural metrics together with either spectral features or vegetation indices. The numbers above bars are relative root-mean square error (RMSEs) and the unit of each attribute related to a biodiversity indicator is presented on the $x$-axis together with the attribute. 
Table 7. Absolute and relative root-mean square error (RMSE) and bias for biodiversity indicators of dead wood, structural heterogeneity, and large deciduous trees. ITC = individual tree-crown approach, semi-ITC = semi-individual tree-crown approach. Predictions were done with the selected three-dimensional (3D) metrics and either selected spectral features or vegetation indices.

\begin{tabular}{|c|c|c|c|c|c|c|c|c|c|c|}
\hline \multirow{2}{*}{\multicolumn{3}{|c|}{ Biodiversity Indicator }} & \multicolumn{4}{|c|}{ ITC } & \multicolumn{4}{|c|}{ Semi-ITC } \\
\hline & & & \multicolumn{2}{|c|}{ With Spectral Features } & \multicolumn{2}{|c|}{ With Vegetation Indices } & \multicolumn{2}{|c|}{ With Spectral Features } & \multicolumn{2}{|c|}{ With Vegetation Indices } \\
\hline & & & Abs & $\%$ & Abs & $\%$ & Abs & $\%$ & Abs & $\%$ \\
\hline \multirow{4}{*}{ Amount of dead wood } & \multirow{2}{*}{$\mathrm{N} / \mathrm{ha}$} & RMSE & 58.39 & 146.86 & 58.36 & 146.78 & 53.30 & 134.05 & 54.87 & 138.01 \\
\hline & & Bias & 39.41 & 99.12 & 39.76 & 100.00 & 27.90 & 70.18 & 27.20 & 68.42 \\
\hline & \multirow{2}{*}{$\mathrm{V}\left(\mathrm{m}^{3} / \mathrm{ha}\right)$} & RMSE & 5.07 & 164.54 & 5.07 & 164.34 & 5.62 & 182.36 & 4.77 & 154.66 \\
\hline & & Bias & 3.04 & 98.47 & 3.08 & 100.00 & 1.74 & 56.38 & 1.71 & 55.55 \\
\hline \multirow{4}{*}{ Structural heterogeneity } & \multirow{2}{*}{ std of dbh $(\mathrm{cm})$} & RMSE & 2.17 & 30.19 & 2.35 & 32.75 & 1.75 & 24.36 & 1.98 & 27.57 \\
\hline & & Bias & 1.01 & 14.05 & 1.05 & 14.58 & -0.03 & -0.43 & 0.19 & 2.61 \\
\hline & \multirow{2}{*}{ std of $H(m)$} & RMSE & 2.38 & 43.26 & 2.41 & 43.97 & 1.70 & 30.91 & 1.61 & 29.34 \\
\hline & & Bias & 1.60 & 29.06 & 1.55 & 28.24 & 0.11 & 1.92 & 0.18 & 3.34 \\
\hline \multirow{2}{*}{ Successional stage } & \multirow{2}{*}{$\mathrm{D}_{\mathrm{g}}(\mathrm{cm})$} & RMSE & 9.63 & 41.73 & 10.99 & 47.64 & 10.77 & 46.68 & 11.98 & 51.95 \\
\hline & & Bias & 7.06 & 30.60 & 7.85 & 34.04 & 7.20 & 31.19 & 9.36 & 40.56 \\
\hline \multirow{4}{*}{$\begin{array}{l}\text { Amount of large } \\
\text { deciduous trees }\end{array}$} & \multirow{2}{*}{ N/ha } & RMSE & 220.37 & 702.05 & 197.52 & 629.27 & 139.40 & 444.08 & 125.78 & 400.71 \\
\hline & & Bias & -166.02 & -528.89 & -158.69 & -505.56 & -100.10 & -318.89 & -93.82 & -298.89 \\
\hline & \multirow{2}{*}{$\mathrm{V}\left(\mathrm{m}^{3} / \mathrm{ha}\right)$} & RMSE & 49.19 & 235.20 & 74.90 & 358.13 & 33.96 & 162.37 & 49.31 & 235.76 \\
\hline & & Bias & -33.80 & -161.63 & -50.99 & -243.80 & -7.28 & -34.83 & -17.91 & -85.61 \\
\hline
\end{tabular}


Table 8. Absolute and relative root-mean square error (RMSE) and bias for biodiversity indicator of species richness assessed with amount of various tree species. ITC $=$ individual tree-crown approach, semi-ITC $=$ semi-individual tree-crown approach. Predictions were done with the selected 3D metrics and either selected spectral features or vegetation indices.

\begin{tabular}{|c|c|c|c|c|c|c|c|c|c|c|c|}
\hline & \multirow{3}{*}{\multicolumn{2}{|c|}{ Biodiversity Indicator }} & & \multicolumn{4}{|c|}{ ITC } & \multicolumn{4}{|c|}{ Semi-ITC } \\
\hline & & & & \multicolumn{2}{|c|}{ With Spectral Features } & \multicolumn{2}{|c|}{ With Vegetation Indices } & \multicolumn{2}{|c|}{ With Spectral Features } & \multicolumn{2}{|c|}{ With Vegetation Indices } \\
\hline & & & & Abs & $\%$ & Abs & $\%$ & Abs & $\%$ & Abs & $\%$ \\
\hline \multirow{24}{*}{ Species richness } & \multirow{12}{*}{$\mathrm{N} / \mathrm{ha}$} & \multirow{2}{*}{ Pine } & RMSE & 354.07 & 137.77 & 323.80 & 125.99 & 367.38 & 142.95 & 370.86 & 144.30 \\
\hline & & & Bias & 105.63 & 41.10 & 99.70 & 38.80 & 149.93 & 58.34 & 164.92 & 64.17 \\
\hline & & \multirow{2}{*}{ Spruce } & RMSE & 407.98 & 88.94 & 443.04 & 96.58 & 349.35 & 76.16 & 375.55 & 81.87 \\
\hline & & & Bias & 277.70 & 60.54 & 296.88 & 64.72 & 175.51 & 38.26 & 172.02 & 37.50 \\
\hline & & \multirow{2}{*}{ Birch } & RMSE & 348.54 & 132.36 & 404.28 & 153.53 & 53.30 & 134.05 & 54.87 & 138.01 \\
\hline & & & Bias & 74.99 & 28.48 & 93.12 & 35.36 & 27.90 & 70.18 & 27.20 & 68.42 \\
\hline & & \multirow{2}{*}{ Aspen } & RMSE & 64.44 & 318.53 & 76.16 & 376.49 & 70.42 & 348.12 & 73.66 & 364.13 \\
\hline & & & Bias & 13.60 & 67.24 & 5.23 & 25.86 & 16.74 & 82.76 & 13.60 & 67.24 \\
\hline & & \multirow{2}{*}{ Alder } & RMSE & 20.38 & 254.12 & 22.07 & 275.12 & 22.90 & 285.50 & 21.68 & 270.27 \\
\hline & & & Bias & 5.58 & 69.57 & 3.14 & 39.13 & 2.79 & 34.78 & 2.79 & 34.78 \\
\hline & & \multirow[b]{2}{*}{ Decid. } & RMSE & 383.16 & 124.69 & 445.38 & 144.94 & 423.90 & 137.95 & 469.33 & 152.73 \\
\hline & & & Bias & 109.88 & 35.76 & 117.20 & 38.14 & 175.80 & 57.21 & 182.08 & 59.25 \\
\hline & \multirow{12}{*}{$\mathrm{V}\left(\mathrm{m}^{3} / \mathrm{ha}\right)$} & \multirow{2}{*}{ Pine } & RMSE & 88.54 & 116.84 & 86.70 & 114.42 & 94.16 & 124.26 & 99.01 & 130.65 \\
\hline & & & Bias & 13.82 & 18.23 & 11.83 & 15.61 & 41.46 & 54.71 & 45.65 & 60.23 \\
\hline & & \multirow{2}{*}{ Spruce } & RMSE & 99.65 & 86.38 & 90.34 & 78.31 & 93.64 & 81.17 & 78.59 & 68.13 \\
\hline & & & Bias & 15.05 & 13.05 & 32.67 & 28.32 & 4.64 & 4.02 & 11.64 & 10.09 \\
\hline & & \multirow{2}{*}{ Birch } & RMSE & 50.67 & 111.29 & 59.63 & 130.95 & 50.32 & 110.52 & 55.44 & 121.77 \\
\hline & & & Bias & -3.54 & -7.76 & -4.88 & -10.71 & 21.78 & 47.84 & 23.20 & 50.96 \\
\hline & & \multirow{2}{*}{ Aspen } & RMSE & 35.96 & 326.30 & 57.29 & 519.82 & 40.51 & 367.53 & 54.92 & 498.27 \\
\hline & & & Bias & 5.64 & 51.16 & -2.53 & -22.93 & 7.36 & 66.80 & 2.11 & 19.17 \\
\hline & & \multirow{2}{*}{ Alder } & RMSE & 2.29 & 288.62 & 4.28 & 539.97 & 2.69 & 338.55 & 2.63 & 331.69 \\
\hline & & & Bias & 0.53 & 66.22 & -0.33 & -41.67 & 0.00 & 0.18 & 0.03 & 4.20 \\
\hline & & \multirow[b]{2}{*}{ Decid. } & RMSE & 51.64 & 89.07 & 85.94 & 148.23 & 70.00 & 120.75 & 83.39 & 143.83 \\
\hline & & & Bias & 3.26 & 5.62 & -7.11 & -12.26 & 29.78 & 51.36 & 25.98 & 44.81 \\
\hline
\end{tabular}



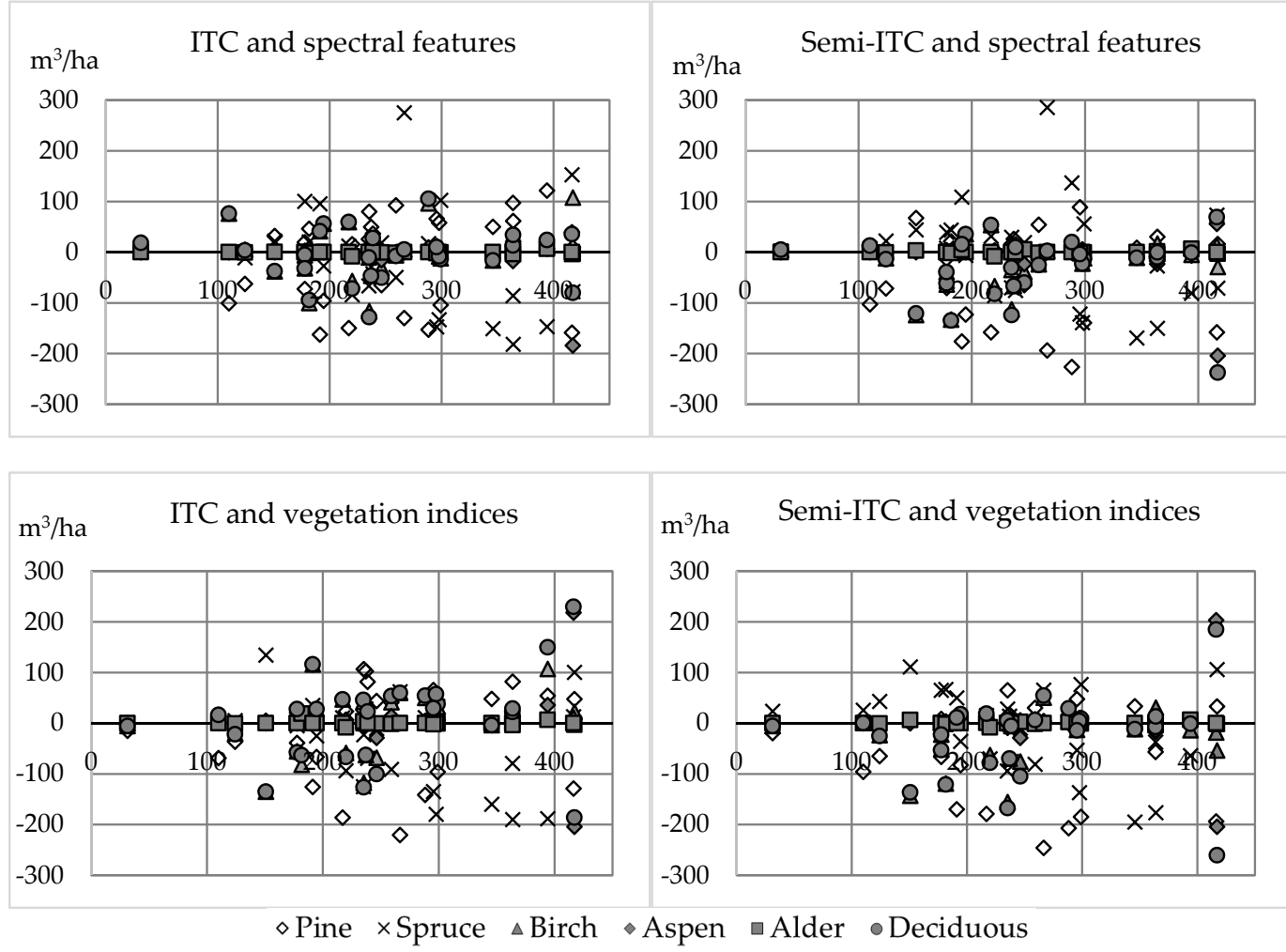

Figure 5. Prediction error of volume of each tree species with ITC (left) and semi-ITC (right) using either spectral features (up) or vegetation indices (bottom) as a function of total volume of a sample plot based on field measurements.

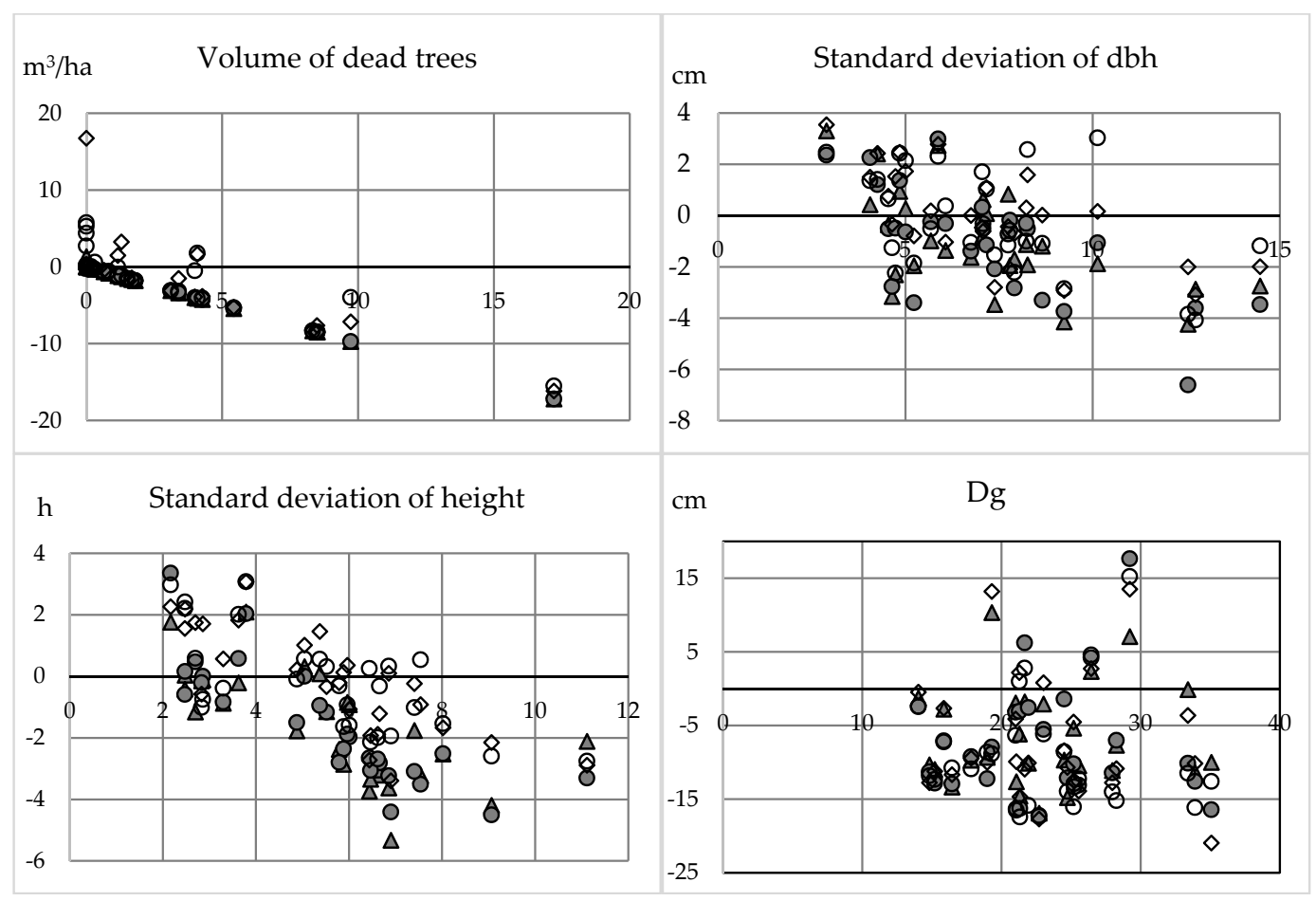

Figure 6. Cont. 


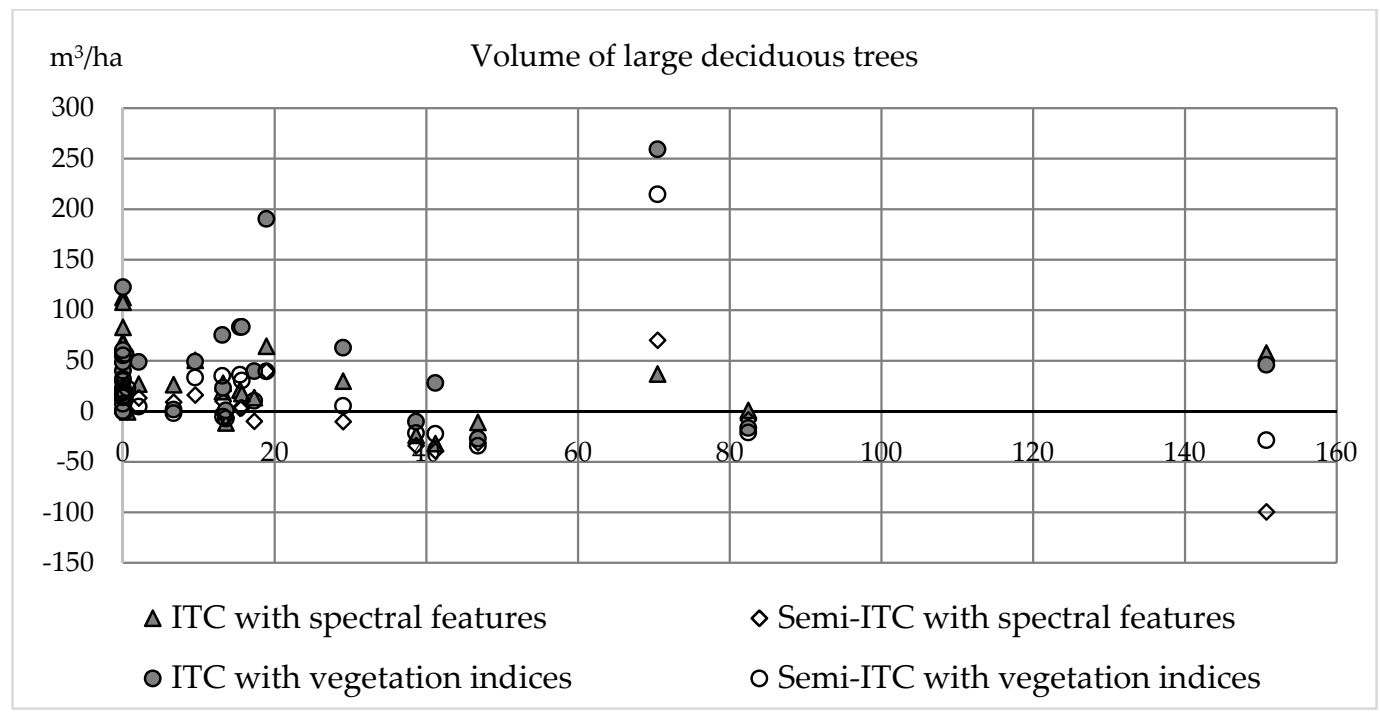

Figure 6. Error of biodiversity indicators as a function of field measured values.

\section{Discussion}

The novel low-cost hyperspectral camera technology based on the tuneable FPI by Senop Ltd. (www.senop.fi) was used in predicting biodiversity indicators at plot level. The FPI-camera is capable of producing freely selectable spectral bands with $1 \mathrm{~nm}$ spectral sampling interval and approximately with $10 \mathrm{~nm}$ spectral resolution (FWHM). Only 22 bands were used due to the limitations of the former version of the camera that was used in the data acquisition for this study. However, the spectral data represented the spectral characteristics of the objects of interest well, thus, we considered the data hyperspectral. The current versions of the camera can be programmed to capture for instance 100 bands with approximately $3 \mathrm{~s}$ imaging interval, thus, producing denser spectral sampling (www.senop.fi).

We captured the UAV datasets using a flight altitude of $400 \mathrm{~m}$ in order to cover the area where the sample plots were located as cost efficiently as possible. This is higher altitude than usually used in UAV flights and special permits were acquired from the local authorities for the flights. The resulting GSD was $25 \mathrm{~cm}$ for the hyperspectral data and $10 \mathrm{~cm}$ for the RGB data. Data acquisition from lower flight altitude would have been less efficient because more flight lines and lower flight speed, as well as more GCPs and more time for image data post-processing would have been required. On the other hand, the resulting spatial resolution of the data would have been finer. For example, the typical flight altitude of $120 \mathrm{~m}$ would have produced GSDs of $3 \mathrm{~cm}$ and $7.5 \mathrm{~cm}$ for the RGB and hyperspectral imagery, respectively. Improved resolution would provide more accurate and detailed geometric and radiometric description of the object that might improve the interpretation accuracy. For example, the study by [64] showed that hyperspectral datasets with $9 \mathrm{~cm}$ GSD outperformed datasets with $50 \mathrm{~cm}$ GSD when identifying spruces suffering of bark beetle infestation at individual tree level. The overall accuracy and Cohen's kappa were $81 \%$ and 0.70 , and $73 \%$ and 0.56 for the GSDs of $9 \mathrm{~cm}$ and $50 \mathrm{~cm}$, respectively, in comparable cases. The finer GSD could also improve the quality of the geometric features extracted from the point clouds. However, in this study, the majority of the trees were relatively mature and large (average height of live trees $15.7 \mathrm{~m}$ ) and the terrain level was obtained from the ALS, thus, we expect that better spatial resolution would not have improved the accuracy in this study. This assumption follows the results by [65] showing that GSDs of 5-30 cm provided stable tree height estimates.

Biodiversity indicators related to forest structure (i.e., maturity and structural complexity through size) were more accurately assessed as compared to indicators that are associated with health status or species (i.e., species richness, the amount of dead wood, and large deciduous trees). The accuracy of individual tree detection affects the estimated variability in tree height, as suppressed trees are 
problematic to identify with photogrammetric point clouds because penetration through canopy is challenging $[44,66,67]$. As there can be more than one tree within a crown segment in the semi-ITC, smaller trees, usually below the main canopy, and covered by adjacent tree crowns, were better represented in the predictions. Thus, structural heterogeneity (i.e., standard deviation of $\mathrm{dbh}$ and height) was more accurately predicted with semi-ITC compared to ITC.

UAV-based photogrammetric point clouds have been used in estimating canopy height $[44,65,68]$, but also plot-level forest inventory attributes [69]. Our aim was to characterize complexity of canopy structure, thus, standard deviation of tree height was assessed. Therefore, the comparison between our results is not straightforward. In [45], however, UAV-based photogrammetric point cloud and canopy height model (CHM) generated were used to assess restoration of tropical forest with various restoration treatments. They determined the average of the absolute deviation of each pixel from the average $\mathrm{CHM}$ height across each treatment as a canopy roughness (i.e., indicator of structural diversity). The RMSE for canopy roughness was reported $0.82 \mathrm{~m}$ when compared to standard deviation of field-measured tree height. In our study, the smallest RMSE $(1.61 \mathrm{~m})$ for standard deviation of tree height was obtained with semi-ITC when vegetation indices were included in the predictions together with Hmax. However, our flight altitude was $400 \mathrm{~m}$, whereas, in [45], it was between $30 \mathrm{~m}$ and $40 \mathrm{~m}$. In addition, tree height varied only from app. $0.5 \mathrm{~m}$ to app. $13 \mathrm{~m}$ in [45] as compared to larger range in our study site between $2.0 \mathrm{~m}$ and $31.9 \mathrm{~m}$. When considering these differences, our results are comparable if not even auspicious. In addition to UAVs, other remote sensing data sets have also been used in estimating structural diversity. In [70], plot-level tree size diversity was modelled through ALS-based features, whereas in [71], structural diversity of urban forests was estimated with various satellite imagery. Both studies conclude that the used remote sensing data sets can be utilized in characterizing structural diversity.

In [69], plot-level estimates for volumes of Scots pine, Norway spruce, and deciduous trees were estimated using similar UAV to this study. They had altitude of about $90 \mathrm{~m}$, which is considerably lower than our $400 \mathrm{~m}$ and did not use ITC, but so-called area-based approach in the predictions. Nevertheless, our results are comparable to theirs as the relative RMSE for pine varied between $34.51 \%$ and $45.66 \%$, but for spruce it was between $57.16 \%$ and $97.58 \%$. Relative RMSE for pine in this study was greater (between $114.42 \%$ and $130.65 \%$ ), but similar for spruce (between $68.13 \%$ and $86.38 \%$ ). Especially with ITC and spectral features, we were able to obtain similar results for deciduous trees (relative RMSE $89.07 \%$ ) to theirs (relative RMSE ranging from $42.00 \%$ to $81.98 \%$ ). In [72], photogrammetric point clouds were utilized to predict total stem volume and stem number at plot level with semi-ITC. The relative RMSE was $46 \%$ for stem density, but it was $25 \%$ and $30 \%$ for volume estimates depending on modelling technique (i.e., multivariate or univariate $\mathrm{kNN}$ ). These results are noticeably better compared to our results.

The amount of large broadleaved trees, as well as the volume of birch, aspen, and alder, were overestimated when compared to other species. In [25], on the other hand, individual tree crowns were identified and tree species was classified with similar UAV to this study. Again, the difference between flight altitude was noteworthy (app. $90 \mathrm{~m}$ vs. $400 \mathrm{~m}$ ). They were able to identify individual tree species of Scots pine, Norway spruce, birch, and larch with classification accuracy varying from $89.5 \%$ to $93.1 \%$ when utilizing the nearest neighbor in their predictions, similar to this study. Their results are, however, reported at tree level classification and we used plot-level volume for each tree as the attributes to be estimated. They reported most errors when differentiating spruce from pine, whereas in this study volume of deciduous trees was overestimated as compared to other tree species. In [73], it was stated that pine could have higher intensity values when mixed with broadleaved species. This is true in our study area and can explain partly the difference in volume estimates of deciduous trees.

Photogrammetric point clouds were used to derive information from vertical structure of Brazilian semideciduous tropical forest in [74], and they concluded that it was possible to classify successional stage with this information. Our results support their findings. In [75], basal-area weighted mean diameter was estimated with relative RMSE of $28 \%$ with ITC, whereas with semi-ITC the relative 
RMSE varied between $12.1 \%$ and $14.3 \%$. Our results showed lower accuracies as the relative RMSE with ITC was $41.73 \%$ and $47.64 \%$ with spectral features and vegetation indices, respectively, and with semi-ITC the corresponding values were $46.68 \%$ and $51.95 \%$. In [72] the relative RMSE was $26 \%$ for quadratic mean diameter.

Semi-ITC was used in predicting species-specific volume at plot level with ALS data in [63] and they reported relative RMSE of $56.46 \%, 47.40 \%, 100.80 \%$, and $209.71 \%$ for pine, spruce, birch, and aspen, respectively. The relative bias for corresponding tree species was $-3.61 \%, 8.64 \%, 40.52 \%$, and $64.39 \%$, respectively. In this study, the relative RMSE was notably larger for all the trees species. Relative bias for spruce was similar in this study (i.e., $4.02 \%$ with spectral features and $10.09 \%$ with vegetation indices), but for all other tree species relative bias was larger when compared to the results of [63].

In [75], on the other hand, ALS data was combined with red-green-infrared, multispectral, and hyperspectral imagery to estimate total volume and species-specific stem number with ITC and semi-ITC. With semi-ITC, the mean relative RMSE for number of pine stems per hectare varied between $34.7 \%$ and $47.8 \%$ depending on whether only ALS was used or a combination of ALS and aerial imagery. Respectively relative RMSE for stem number of spruce was reported to vary from $33.2 \%$ to $51.5 \%$, and for deciduous trees from $110.2 \%$ to $144.8 \%$. In this study, the relative RMSE for pine and spruce were larger but for deciduous trees the relative RMSEs were similar as compared to the results by [75]. The relative RMSE value based on ITC, as reported by [75], for stem number of spruce varied between $80.7 \%$ and $83.5 \%$, for pine between $55.3 \%$ and $60.0 \%$, and for deciduous trees between $102.9 \%$ and $121.3 \%$. Again, our results are not as accurate for pine and spruce, but were similar for deciduous trees.

Also, in [76], ITC and semi-ITC were compared when predicting species composition using ALS only and combining ALS and colour infrared, multispectral, and hyperspectral aerial imagery. However, they estimated plot-level proportion of pine, spruce and deciduous trees and comparison to their results is not conceivable.

ALS data were utilized in [34] to predict plot-level volume for dead trees. They reported a relative RMSE of $78.8 \%$ for dead wood volume of standing trees, which is less than in our predictions. However, it should be noted that they used bias correction and estimation was carried out for each plot with so-called area-based approach, no individual trees were identified but variables from ALS data were calculated for each plot and regression models for the amount of dead wood at plot level were developed. In [77], fallen trees were identified with two ALS data sets from different years using ITC. Their results were presented as absolute volume (i.e., $\mathrm{m}^{3}$ ) and predictions resulted in overestimates varying between $21.8 \%$ and $28.3 \%$ for conifer and underestimates varying from $21.2 \%$ to $252.7 \%$ for deciduous trees at stand level. Relative RMSE reported in this study for mean volume per hectare of deciduous trees fall within the error range in [77].

Structural attributes describing biodiversity were more accurately assessed with semi-ITC when compared to ITC. Our results for structural heterogeneity were comparable with other studies using different remote sensing datasets and modelling approaches. The accuracies for species-specific volume, which can be used as proxy for a biodiversity indicator, such as species diversity, or volume of dead trees reported here were moderate. However, they are in line with previous studies using various remote sensing datasets for estimating volume of various tree species. Thus, this study provided new insight for biodiversity assessment to compliment field measurements at plot level where UAV-based photogrammetric point clouds and hyperspectral imagery have not yet been widely studied.

\section{Conclusions}

We used spectral and 3D features based on photogrammetric point clouds and hyperspectral imaging in assessing plot-level biodiversity indicators. When biodiversity was assessed through structural variability or successional stage, the predictions based on photogrammetric point clouds and hyperspectral information from a UAV were the most reliable. Semi-ITC produced more accurate 
results for the indicators of structural heterogeneity, and large deciduous trees when compared to ITC. Based on our results, biodiversity indicators derived from the data acquired by a UAV differed from the indicators derived from the field measurements at sample plot level. However, the potential of a small UAV in large area biodiversity assessment through multi-phase sampling should be further investigated. Further studies are especially required to verify how much the presumably decreased accuracy in biodiversity indicators at sample plot level affects the large area estimates and can that effect be compensated by more comprehensive sampling, for which UAVS provide a cost-efficient alternative.

Acknowledgments: The study was funded by the Academy of Finland through a project "Unmanned Airborne Vehicle-based 4D Remote Sensing for Mapping Rain Forest Biodiversity and Its Change in Brazil" (Decision number 273806) and the Centre of Excellence in Laser Scanning Research (project number 272195). The authors would also like to thank Häme University of Applied Science for supporting our research activities at Evo study site, Senop Oy for providing us the FPI hyperspectral camera, and Niko Viljanen, Sakari Tuominen and Ilkka Pölönen for their support during the UAV data capture flights. Senior researchers Paula Litkey and Raquel Oliveira are thanked for their support in point cloud processing.

Author Contributions: E.H., M.H., M.V. and J.H. designed the experiment; E.H., R.N., T.R. and T.H. acquired the remote sensing data and processed the data; V.L. was responsible for the field reference; N.S. analyzed the data and wrote the first draft of the paper; M.A.W. A.M.G.T., N.N.I., E.A.W.R. and R.B.G. provided scientific guidance. All authors assisted in writing and improving the paper.

Conflicts of Interest: The authors declare no conflict of interest. The founding sponsors had no role in the design of the study; in the collection, analyses, or interpretation of data; in the writing of the manuscript, and in the decision to publish the results.

\section{References}

1. Gaston, K.J. Global patterns in biodiversity. Nature 2000, 405, 220-227. [CrossRef] [PubMed]

2. Huston, M.A. Biological Diversity: The Coexistence of Species; Cambridge University Press: Cambridge, UK, 1994.

3. Rosenzweig, M.L. Species Diversity in Space and Time; Cambridge University Press: Cambridge, UK, 1995.

4. Kimmins, J. Biodiversity and its relationship to ecosystem health and integrity. For. Chron. 1997, 73, $229-232$. [CrossRef]

5. Alkemade, R.; van Oorschot, M.; Miles, L.; Nellemann, C.; Bakkenes, M.; ten Brink, B. Globio3: A framework to investigate options for reducing global terrestrial biodiversity loss. Ecosystems 2009, 12, 374-390. [CrossRef]

6. MacDicken, K.; Jonsson, Ö.; Piña, L.; Maulo, S.; Contessa, V.; Adikari, Y.; Garzuglia, M.; Lindquist, E.; Reams, G.; D'Annunzio, R. Global Forest Resources Assessment 2015: How Are the World's Forests Changing? United Nations: Bonn, Germany, 2016.

7. Sala, O.E.; Stuart Chapin, F., III; Armesto, J.J.; Berlow, E.; Bloomfield, J.; Dirzo, R.; Huber-Sanwald, E.; Huenneke, L.F.; Jackson, R.B.; Kinzig, A.; et al. Global biodiversity scenarios for the year 2100. Science 2000, 287, 1770-1774. [CrossRef] [PubMed]

8. Sanderson, E.W.; Jaiteh, M.; Levy, M.A.; Redford, K.H.; Wannebo, A.V.; Woolmer, G. The human footprint and the last of the wild. BioScience 2002, 52, 891-904. [CrossRef]

9. Sarukhan, J.; Whyte, A.E.; Hassan, R.E.; Scholes, R.E.; Ash, N.E.; Carpenter, S.T.E.; Pingali, P.L.E.; Bennett, E.M.E.; Zurek, M.B.E.; Chopra, K.E.; et al. Millenium Ecosystem Assessment: Ecosystems and Human Well-Being; Island Press: Washington, DC, USA, 2005.

10. Burton, P.J.; Messier, C.; Weetman, G.F.; Prepas, E.E.; Adamowicz, W.L.; Tittler, R. The current state of boreal forestry and the drive for change. In Towards Sustainable Management of Boreal Forests; Burton, P.J., Messier, C., Smith, D.W., Adamowicz, W.L., Eds.; NRC Research Press: Ottawa, ON, Canada, 2003; p. 1039.

11. Kuuluvainen, T. Natural variability of forests as a reference for restoring and managing biological diversity in boreal Fennoscandia. Silva Fenn. 2002, 36, 97-125. [CrossRef]

12. Esseen, P.-A.; Ehnström, B.; Ericson, L.; Sjöberg, K. Boreal forests. Ecol. Bull. 1997, 46, 16-47.

13. Kuusinen, M. Epiphyte flora and diversity on basal trunks of six old-growth forest tree species in southern and middle boreal Finland. Lichenologist 1996, 28, 443-463. [CrossRef]

14. Kuusinen, M. Epiphytic lichen flora and diversity on Populus tremula in old-growth and managed forests of southern and middle boreal Finland. Ann. Bot. Fenn. 1994, 31, 245-260. 
15. Siitonen, J. Forest management, coarse woody debris and saproxylic organisms: Fennoscandian boreal forests as an example. Ecol. Bull. 2001, 49, 11-41.

16. Willson, M.F. Avian community organization and habitat structure. Ecology 1974, 55, 1017-1029. [CrossRef]

17. Lähde, E.; Laiho, O.; Norokorpi, Y.; Saksa, T. Stand structure as the basis of diversity index. For. Ecol. Manag. 1999, 115, 213-220. [CrossRef]

18. Staudhammer, C.L.; LeMay, V.M. Introduction and evaluation of possible indices of stand structural diversity. Can. J. For. Res. 2001, 31, 1105-1115. [CrossRef]

19. Kuuluvainen, T.; Linkosalo, T. Estimation of a spatial tree-influence model using iterative optimization. Ecol. Model. 1998, 106, 63-75. [CrossRef]

20. Duro, D.C.; Coops, N.C.; Wulder, M.A.; Han, T. Development of a large area biodiversity monitoring system driven by remote sensing. Prog. Phys. Geogr. 2007, 31, 235-260. [CrossRef]

21. Pykäläinen, J.; Hiltunen, V.; Leskinen, P. Complementary use of voting methods and interactive utility analysis in participatory strategic forest planning: Experiences gained from western Finland. Can. J. For. Res. 2007, 37, 853-865. [CrossRef]

22. Nagendra, H. Using remote sensing to assess biodiversity. Int. J. Remote Sens. 2001, 22, 2377-2400. [CrossRef]

23. Müller, J.; Vierling, K. Assessing biodiversity by airborne laser scanning. In Forestry Applications of Airborne Laser Scanning; Maltamo, M., Næsset, E., Vauhkonen, J., Eds.; Springer: Dordrecth, The Netherlands, 2014; pp. 357-374.

24. Turner, W.; Spector, S.; Gardiner, N.; Fladeland, M.; Sterling, E.; Steininger, M. Remote sensing for biodiversity science and conservation. Trends Ecol. Evol. 2003, 18, 306-314. [CrossRef]

25. Nevalainen, O.; Honkavaara, E.; Tuominen, S.; Viljanen, N.; Hakala, T.; Yu, X.; Hyyppä, J.; Saari, H.; Pölönen, I.; Imai, N.N. Individual tree detection and classification with UAV-based photogrammetric point clouds and hyperspectral imaging. Remote Sens. 2017, 9, 185. [CrossRef]

26. Säynäjoki, R.; Packalén, P.; Maltamo, M.; Vehmas, M.; Eerikäinen, K. Detection of aspens using high resolution aerial laser scanning data and digital aerial images. Sensors 2008, 8, 5037-5054. [CrossRef] [PubMed]

27. Junttila, S.; Kaasalainen, S.; Vastaranta, M.; Hakala, T.; Nevalainen, O.; Holopainen, M. Investigating bi-temporal hyperspectral LiDAR measurements from declined trees-Experiences from laboratory test. Remote Sens. 2015, 7, 13863. [CrossRef]

28. Kantola, T.; Vastaranta, M.; Yu, X.; Lyytikainen-Saarenmaa, P.; Holopainen, M.; Talvitie, M.; Kaasalainen, S.; Solberg, S.; Hyyppa, J. Classification of defoliated trees using tree-level airborne laser scanning data combined with aerial images. Remote Sens. 2010, 2, 2665. [CrossRef]

29. Clawges, R.; Vierling, K.; Vierling, L.; Rowell, E. The use of airborne lidar to assess avian species diversity, density, and occurrence in a pine/aspen forest. Remote Sens. Environ. 2008, 112, 2064-2073. [CrossRef]

30. Hinsley, S.; Hill, R.; Gaveau, D.; Bellamy, P. Quantifying woodland structure and habitat quality for birds using airborne laser scanning. Funct. Ecol. 2002, 16, 851-857. [CrossRef]

31. Miura, N.; Jones, S.D. Characterizing forest ecological structure using pulse types and heights of airborne laser scanning. Remote Sens. Environ. 2010, 114, 1069-1076. [CrossRef]

32. Morsdorf, F.; Mårell, A.; Koetz, B.; Cassagne, N.; Pimont, F.; Rigolot, E.; Allgöwer, B. Discrimination of vegetation strata in a multi-layered mediterranean forest ecosystem using height and intensity information derived from airborne laser scanning. Remote Sens. Environ. 2010, 114, 1403-1415. [CrossRef]

33. Vehmas, M.; Eerikäinen, K.; Peuhkurinen, J.; Packalén, P.; Maltamo, M. Identification of boreal forest stands with high herbaceous plant diversity using airborne laser scanning. For. Ecol. Manag. 2009, 257, 46-53. [CrossRef]

34. Pesonen, A.; Maltamo, M.; Eerikäinen, K.; Packalèn, P. Airborne laser scanning-based prediction of coarse woody debris volumes in a conservation area. For. Ecol. Manag. 2008, 255, 3288-3296. [CrossRef]

35. Vehmas, M.; Packalén, P.; Maltamo, M.; Eerikäinen, K. Using airborne laser scanning data for detecting canopy gaps and their understory type in mature boreal forest. Ann. For. Sci. 2011, 68, 825-835. [CrossRef]

36. Vauhkonen, J.; Imponen, J. Unsupervised classification of airborne laser scanning data to locate potential wildlife habitats for forest management planning. Forestry 2016, 89, 350-363. [CrossRef]

37. Goodbody, T.R.; Coops, N.C.; Marshall, P.L.; Tompalski, P.; Crawford, P. Unmanned aerial systems for precision forest inventory purposes: A review and case study. For. Chron. 2017, 93, 71-81. [CrossRef]

38. Pajares, G. Overview and current status of remote sensing applications based on unmanned aerial vehicles (UAVs). Photogramm. Eng. Remote Sens. 2015, 81, 281-329. [CrossRef] 
39. Torresan, C.; Berton, A.; Carotenuto, F.; Di Gennaro, S.F.; Gioli, B.; Matese, A.; Miglietta, F.; Vagnoli, C.; Zaldei, A.; Wallace, L. Forestry applications of UAVs in europe: A review. Int. J. Remote Sens. 2017, 38, 2427-2447.

40. De Oliveira, R.A.; Tommaselli, A.M.; Honkavaara, E. Using Hyperspectral Frame Images from Unmanned Airborne Vehicle for Detailed Measurement of Boreal Forest 3d Structure. IOP Conf. Ser. Earth Environ. Sci. 2016, 44, 042029. [CrossRef]

41. Puliti, S.; Ørka, H.O.; Gobakken, T.; Næsset, E. Inventory of small forest areas using an unmanned aerial system. Remote Sens. 2015, 7, 9632-9654. [CrossRef]

42. Inoue, T.; Nagai, S.; Yamashita, S.; Fadaei, H.; Ishii, R.; Okabe, K.; Taki, H.; Honda, Y.; Kajiwara, K.; Suzuki, R. Unmanned aerial survey of fallen trees in a deciduous broadleaved forest in eastern japan. PLOS ONE 2014, 9, e109881. [CrossRef] [PubMed]

43. Getzin, S.; Nuske, R.S.; Wiegand, K. Using unmanned aerial vehicles (UAV) to quantify spatial gap patterns in forests. Remote Sens. 2014, 6, 6988-7004. [CrossRef]

44. Wallace, L.; Lucieer, A.; Malenovský, Z.; Turner, D.; Vopěnka, P. Assessment of forest structure using two UAV techniques: A comparison of airborne laser scanning and structure from motion (SfM) point clouds. Forests 2016, 7, 62. [CrossRef]

45. Zahawi, R.A.; Dandois, J.P.; Holl, K.D.; Nadwodny, D.; Reid, J.L.; Ellis, E.C. Using lightweight unmanned aerial vehicles to monitor tropical forest recovery. Biol. Conserv. 2015, 186, 287-295. [CrossRef]

46. Näsi, R.; Honkavaara, E.; Lyytikäinen-Saarenmaa, P.; Blomqvist, M.; Litkey, P.; Hakala, T.; Viljanen, N.; Kantola, T.; Tanhuanpää, T.; Holopainen, M. Using UAV-based photogrammetry and hyperspectral imaging for mapping bark beetle damage at tree-level. Remote Sens. 2015, 7, 15467-15493. [CrossRef]

47. Nilsson, M. Estimation of tree heights and stand volume using an airborne lidar system. Remote Sens. Environ. 1996, 56, 1-7. [CrossRef]

48. Zhang, J.; Hu, J.; Lian, J.; Fan, Z.; Ouyang, X.; Ye, W. Seeing the forest from drones: Testing the potential of lightweight drones as a tool for long-term forest monitoring. Biol. Conserv. 2016, 198, 60-69. [CrossRef]

49. Getzin, S.; Wiegand, K.; Schöning, I. Assessing biodiversity in forests using very high-resolution images and unmanned aerial vehicles. Methods Ecol. Evol. 2012, 3, 397-404. [CrossRef]

50. Anderson, K.; Gaston, K.J. Lightweight unmanned aerial vehicles will revolutionize spatial ecology. Front. Ecol. Environ. 2013, 11, 138-146. [CrossRef]

51. Dandois, J.P.; Ellis, E.C. High spatial resolution three-dimensional mapping of vegetation spectral dynamics using computer vision. Remote Sens. Environ. 2013, 136, 259-276. [CrossRef]

52. Laasasenaho, J. Taper Curve and Volume Functions for Pine, Spruce and Birch; Metsäntutkimuslaitos: Helsinki, Finland, 1982.

53. Repola, J. Biomass equations for birch in Finland. Silva Fenn. 2008, 42, 605-624. [CrossRef]

54. Repola, J. Biomass equations for scots pine and norway spruce in Finland. Silva Fenn. 2009, 43, 625-647. [CrossRef]

55. Honkavaara, E.; Saari, H.; Kaivosoja, J.; Pölönen, I.; Hakala, T.; Litkey, P.; Mäkynen, J.; Pesonen, L. Processing and assessment of spectrometric, stereoscopic imagery collected using a lightweight UAV spectral camera for precision agriculture. Remote Sens. 2013, 5, 5006. [CrossRef]

56. Pons, J.-P.; Keriven, R.; Faugeras, O. Multi-view stereo reconstruction and scene flow estimation with a global image-based matching score. Int. J. Comput. Vis. 2007, 72, 179-193. [CrossRef]

57. Smith, G.M.; Milton, E.J. The use of the empirical line method to calibrate remotely sensed data to reflectance. Int. J. Remote Sens. 1999, 20, 2653-2662. [CrossRef]

58. Miyoshi, G.T.; Imai, N.N.; Tommaselli, A.M.G.; Honkavaara, E.; Näsi, R.; Moriya, É.A.S. Radiometric block adjustment of hyperspectral image blocks in the brazilian environment. Int. J. Remote Sens. 2018. [CrossRef]

59. Hirschmugl, M.; Ofner, M.; Raggam, J.; Schardt, M. Single tree detection in very high resolution remote sensing data. Remote Sens. Environ. 2007, 110, 533-544. [CrossRef]

60. Horler, D.N.H.; Dockray, M.; Barber, J. The red edge of plant leaf reflectance. Int. J. Remote Sens. 1983, 4, 273-288. [CrossRef]

61. Breiman, L. Random forests. Mach. Learn. 2001, 45, 5-32. [CrossRef]

62. Belgiu, M.; Drăguț, L. Random forest in remote sensing: A review of applications and future directions. ISPRS J. Photogramm. Remote Sens. 2016, 114, 24-31. [CrossRef] 
63. Breidenbach, J.; Næsset, E.; Lien, V.; Gobakken, T.; Solberg, S. Prediction of species specific forest inventory attributes using a nonparametric semi-individual tree crown approach based on fused airborne laser scanning and multispectral data. Remote Sens. Environ. 2010, 114, 911-924. [CrossRef]

64. Näsi, R.; Honkavaara, E.; Blomqvist, M.; Lyytikäinen-Saarenmaa, P.; Hakala, T.; Viljanen, N.; Kantola, T.; Holopainen, M. Remote sensing of bark beetle damage in urban forests at individual tree level using a novel hyperspectral camera from UAV and aircraft. Urban For. Urban Green. 2018, 30, 72-83. [CrossRef]

65. Zarco-Tejada, P.J.; Diaz-Varela, R.; Angileri, V.; Loudjani, P. Tree height quantification using very high resolution imagery acquired from an unmanned aerial vehicle (UAV) and automatic 3D photo-reconstruction methods. Eur. J. Agron. 2014, 55, 89-99. [CrossRef]

66. Vastaranta, M.; Wulder, M.A.; White, J.C.; Pekkarinen, A.; Tuominen, S.; Ginzler, C.; Kankare, V.; Holopainen, M.; Hyyppä, J.; Hyyppä, H. Airborne laser scanning and digital stereo imagery measures of forest structure: Comparative results and implications to forest mapping and inventory update. Can. J. Remote Sens. 2013, 39, 382-395. [CrossRef]

67. White, J.; Wulder, M.; Vastaranta, M.; Coops, N.; Pitt, D.; Woods, M. The utility of image-based point clouds for forest inventory: A comparison with airborne laser scanning. Forests 2013, 4, 518. [CrossRef]

68. Dandois, J.; Olano, M.; Ellis, E. Optimal altitude, overlap, and weather conditions for computer vision UAV estimates of forest structure. Remote Sens. 2015, 7, 13895. [CrossRef]

69. Tuominen, S.; Balazs, A.; Honkavaara, E.; Pölönen, I.; Saari, H.; Hakala, T.; Viljanen, N. Hyperspectral UAV -imagery and photogrammetric canopy height model in estimating forest stand variables. Silva Fenn. 2017, 51, 7721. [CrossRef]

70. Ozdemir, I.; Donoghue, D.N.M. Modelling tree size diversity from airborne laser scanning using canopy height models with image texture measures. For. Ecol. Manag. 2013, 295, 28-37. [CrossRef]

71. Ozkan, U.Y.; Ozdemir, I.; Demirel, T.; Saglam, S.; Yesil, A. Comparison of satellite images with different spatial resolutions to estimate stand structural diversity in urban forests. J. For. Res. 2017, 28, 805-814. [CrossRef]

72. Rahlf, J.; Breidenbach, J.; Solberg, S.; Astrup, R. Forest parameter prediction using an image-based point cloud: A comparison of semi-ITC with ABA. Forests 2015, 6, 4059. [CrossRef]

73. Korpela, I.; Ørka, H.O.; Maltamo, M.; Tokola, T.; Hyyppä, J. Tree species classification using airborne lidar-effects of stand and tree parameters, downsizing of training set, intensity normalization, and sensor type. Silva Fenn. 2010, 44, 319-339. [CrossRef]

74. Berveglieri, A.; Tommaselli, A.M.G.; Imai, N.N.; Ribeiro, E.A.W.; Guimaraes, R.B.; Honkavaara, E. Identification of successional stages and cover changes of tropical forest based on digital surface model analysis. IEEE J. Sel. Top. Appl. Earth Obs. Remote Sens. 2016, 9, 5385-5397. [CrossRef]

75. Bergseng, E.; Ørka, H.O.; Næsset, E.; Gobakken, T. Assessing forest inventory information obtained from different inventory approaches and remote sensing data sources. Ann. For. Sci. 2015, 72, 33-45. [CrossRef]

76. Ørka, H.O.; Dalponte, M.; Gobakken, T.; Næsset, E.; Ene, L.T. Characterizing forest species composition using multiple remote sensing data sources and inventory approaches. Scand. J. For. Res. 2013, 28, 677-688. [CrossRef]

77. Tanhuanpää, T.; Kankare, V.; Vastaranta, M.; Saarinen, N.; Holopainen, M. Monitoring downed coarse woody debris through appearance of canopy gaps in urban boreal forests with bitemporal ALS data. Urban For. Urban Green. 2015, 14, 835-843. [CrossRef]

(C) 2018 by the authors. Licensee MDPI, Basel, Switzerland. This article is an open access article distributed under the terms and conditions of the Creative Commons Attribution (CC BY) license (http:/ / creativecommons.org/licenses/by/4.0/). 